\title{
Granger causality analysis of deviation in total electron content during geomagnetic storms in the equatorial region
}

\author{
Sumitra lyer $^{1^{*}}$ (iD) and Alka Mahajan ${ }^{2}$
}

\author{
* Correspondence: \\ sumitraiyer2017@gmail.com \\ ${ }^{1}$ Department of Electronics and \\ Communication, Nirma Institute of \\ Technology, Ahmedabad, Gujarat, \\ India \\ Full list of author information is \\ available at the end of the article
}

\begin{abstract}
The total electron content (TEC) in the ionosphere widely influences Global Navigation Satellite Systems (GNSS) especially for critical applications by inducing localized positional errors in the GNSS measurements. These errors can be mitigated by measuring TEC from stations located around the world at various temporal and spatial scales and using them for advanced forecasting of TEC. The TEC can be used as a tool in understanding space weather phenomena such as geomagnetic storms which cause disruptions in the ionosphere. This paper examines the causal relationship between perturbations in TEC caused by geomagnetic storms. The causality between two geomagnetic indices auroral electrojet (AE) and disturbed storm index (Dst) and TEC is investigated using Granger causality at two low-latitude stations, Bangalore and Hyderabad. The outcomes of this study strengthen the regional understanding and modeling of ionospheric parameters which can contribute towards the global efforts for modeling and reducing the ionospheric effects on trans-ionospheric communication and navigation. The causal inferences combined with the data-driven model can be useful in identifying the correct and informative physical quantities to improve the forecasting models.
\end{abstract}

Keywords: Geomagnetic storm, lonosphere, Total electron content, Global Positioning System, Granger causality, Cointegration

\section{Introduction}

The changes in the solar wind and interplanetary medium's physical conditions due to the solar activity result in several space weather phenomena such as geomagnetic storms and substorms which causes large magnetic field perturbations and disturbances in the near-Earth environment [1]. The technologies, such as the Global Positioning System (GPS), which play an important role in navigation, are severely affected by these disturbances. Therefore, it is important to mitigate the damages and errors caused due to these phenomena. Also, it is necessary to get a deeper knowledge of the physical processes responsible for generating such disturbances in the near-Earth environment and model and forecast their complex behavior. This is attempted by investigating dependencies between the parameters defining the geomagnetic storms

(c) The Author(s). 2021 Open Access This article is licensed under a Creative Commons Attribution 4.0 International License, which permits use, sharing, adaptation, distribution and reproduction in any medium or format, as long as you give appropriate credit to the original author(s) and the source, provide a link to the Creative Commons licence, and indicate if changes were made. The images or other third party material in this article are included in the article's Creative Commons licence, unless indicated otherwise in a credit line to the material. If material is not included in the article's Creative Commons licence and your intended use is not permitted by statutory regulation or exceeds the permitted use, you will need to obtain permission directly from the copyright holder. To view a copy of this licence, visit http://creativecommons.org/licenses/by/4.0/. The Creative Commons Public Domain Dedication waiver (http://creativecommons.org/publicdomain/zero/1.0/) applies to the data made available in this article, unless otherwise stated in a credit line to the data. 
namely disturbed storm index (Dst) and auroral electrojet index (AE) and the TEC which defines the dynamics of the ionosphere which impacts the positional accuracy. The causality between the variables is evaluated in this study. The details about the ionosphere TEC and geomagnetic indices are explained in the next section.

\section{Ionosphere}

The ionosphere is a region in the upper atmosphere which extends from around 50 to $1000 \mathrm{~km}$ height and is characterized by partially ionized plasma [2]. The ionosphere is described by the TEC in the layer. The TEC is the total number of electrons present along a path between a radio transmitter and receiver. It is measured in electrons per square meter. By convention, 1 TEC Unit or 1 TECU $=10^{16}$ electrons $/ \mathrm{m}^{2}$.

The TEC is estimated from Global Navigation Satellite System (GNSS) observables and is an important tool in studying the space weather impacts. The TEC in the ionosphere depends on the solar activity like solar flares, coronal mass ejections, high-speed solar wind, solar cycle, solar maxima, and minima. As these solar activities vary with time and have different impacts at different locations, therefore, the TEC also varies due to local time, latitude, longitude, season, geomagnetic conditions, and solar cycle and exhibits temporal and spatial variation. The TEC is found to be maximum near the equator and tapering at poles. The seasonal effects are also observed in TEC due to the movement of the Earth around the Sun. Furthermore, the electron density is linked to the 11-year solar cycle, and during this cycle, it goes through a maximum when the ionosphere is more likely to be disturbed, and the electron density much higher and unpredictable as compared to a quiet day [3]. The daily distribution of TEC also frequently gets affected by geomagnetic storms, during the high solar activity period.

The ionosphere attributes to one of the largest errors in GPS positioning. Apart from positional error, the ionosphere also causes Faraday rotation and bending of radio waves of GPS signal. The irregularity in the ionosphere also leads to rapid fluctuations in signal amplitude/phase or scintillations. The dispersive nature of the ionosphere adds to the complexity and makes the positional error dependent on the frequency of the incoming signal [4]. This dependence is described in Eq. 1 and is obtained from the Appleton and Hartree general equation for the ionosphere's refractive index [5].

$$
n_{\text {iono }}=1-\frac{1}{2} \times\left(\frac{f \text { plasma }}{f \text { signal }}\right)^{2}=1-40.3 \times \frac{N}{f^{2}}
$$

where $n_{\text {iono }}$ is the refractive index, $f_{\text {plasma }}$ the plasma frequency, $N$ is the electron density, and $f_{\text {signal }}$ is the incoming signal frequency. This Eq. 1 is modified and used to evaluate the group delay of a ray path crossing the ionosphere, which is given by Eq. 2

$$
y 1=40.3 \times \frac{\text { TEC }}{f \text { signal }^{2}}
$$

For a single-frequency receiver on $L 1$ frequency, positional error due to group delay is minimized using a correction code. This code emulates the spatial and temporal variations and is broadcasted to the receivers. Several models have been proposed and the Klobuchar model is being currently used in GPS receivers. However, in a dual- 
frequency receiver, the TEC is computed at two different frequencies and error is eliminated [6]. The TEC estimation for a dual-frequency receiver at $L 1$ and $L 2$ frequencies is shown in Eq. 3 where $L_{1}$ is given as $1575.42 \mathrm{MHz}$ and $L_{2} 1227.6 \mathrm{MHz}$ and $P 1$ and $P 2$ are group path lengths.

$$
\mathrm{TEC}=\frac{1}{40.3}\left[\frac{L 1^{2} \cdot L 2^{2}}{L 1^{2}-L 2^{2}}\right](P 1-P 2)
$$

Thus, TEC is an important parameter to understand the dynamics of the ionosphere. The TEC has a linear relationship with the positional error and 1 TECU of electron content produces a range error of $0.16 \mathrm{~m}$ at $L 1$ frequency [7].

The ionosphere is one of the largest obstacles for the Global Positioning System (GPS) to become the primary navigational aid for critical applications and can cause positioning errors, which may be more than $50 \mathrm{~m}$. As seen above, these errors can be eliminated in dual-frequency receivers. However, for single-frequency receivers, these errors can be only reduced by applying fixed corrections based on GNSS observables. For equatorial regions, due to equatorial anomaly and complex spatio-temporal variations in TEC, furthermore, the space weather phenomena like geomagnetic storms cause unpredictable irregularities in the ionosphere causing deviation in TEC pattern. Although there are several geomagnetic indices available to explain the strength of the geomagnetic storms, they are of little use in describing the deviation in the TEC pattern directly. Hence, there is a need to devise a method that can explain the impact of geomagnetic storms on TEC. This paper investigates the causality method to study the impact of a geomagnetic storm on TEC.

\section{Geomagnetic storms and geomagnetic indices}

A geomagnetic storm is one of the major space weather activities which affects the TEC and causes deviation in the TEC. A geomagnetic storm is a disturbance in the magnetosphere that may cause a sudden change in electron density. The Earth's magnetosphere, thermosphere, and ionosphere are driven by the energy emitted from the Sun. The solar wind transfers its wind energy to the Earth's magnetosphere through magnetic reconnection which leads to geomagnetic storms. These slow and fast solar winds from the coronal region also lead to powerful solar events like coronal mass ejections (CMEs) from the Sun [8] and the corotating interaction regions (CIRs). The CMEs are the result of plasma outbursts from the Sun's active region [9]. The CMEs interact with the solar wind and interplanetary magnetic field of the Earth. The southward-directed solar magnetic field interacts strongly with the oppositely oriented magnetic field of the Earth and results in geomagnetic storms. The severe geomagnetic storms lead to anomalous changes in the ionospheric TEC, resulting in frequent amplitude and phase fluctuations. They may also cause cycle slips, amplitude, and phase scintillations, or even loss of lock. Such events not only affect the determination of the position of the receiver, but also the velocity and time of GPS receivers.

A geomagnetic storm may lead to an increase or decrease in the electron density as compared to quiet days when solar and geomagnetic activities are low. Thus, a geomagnetic disturbance may cause a positive ionospheric storm or a negative ionospheric storm. The impact of the geomagnetic storm on TEC depends on the phase and origin 
of the storm. A positive ionospheric storm is seen during the main phase, while in the recovery phase, negative storms are pronounced at all latitudes [10]. Positive storm effects with enhanced TEC are observed at geomagnetically low and mid-latitudes in the daytime, and negative storm effects are observed near the geomagnetic equator [11].

The TEC in the equatorial region is also impacted by the equatorial anomaly, which causes TEC accumulation at certain latitudes due to the formation of crests. This is primarily due to the equatorial electrojet (EEJ), which is caused due to vertical EXB drift leading to the fountain effect. The entire phenomenon is dependent on the EEJ and found to be more pronounced during the high solar activity period or equinox months. Hence, the geomagnetic storm effects are far more pronounced in the equatorial regions.

The strength and impact of geomagnetic disturbances are estimated using geomagnetic indices like $\mathrm{Kp}$, Dst, and $\mathrm{AE}$, to name a few [12]. In this study, two indices $\mathrm{AE}$ and Dst are selected. Both the indices are available at 1-h interval while Kp index is a 3-hourly index. Furthermore, there is a good correlation between Dst and AE; hence, $\mathrm{AE}$ and Dst are selected for the study. The magnitude of these indices is determined using the horizontal $\mathrm{H}$ component of the geomagnetic field. These indices have a pattern characteristic pattern during quiet and disturbed conditions.

The AE index characterizes the intensity of the auroral zone currents or auroral electrojet. It is the difference between the largest negative and positive $\mathrm{H}$ component variations, the $\mathrm{AL}$ and $\mathrm{AU}$ indices. The $\mathrm{AE}$ index uses magnetograms of the $\mathrm{H}$ component. This is collected from twelve observatories located over the longitude in the northern hemisphere at auroral or subauroral latitudes [13]. In a quiet time, this index's value is tens of $\mathrm{nT}$, and during storms and substorms, it increases to several hundred and more than a thousand nano-Tesla (nT).

The Dst index is the globally averaged value of the horizontal component of the Earth's magnetic field at the magnetic equator from a few magnetometer stations [14]. The Dst is computed once per hour and reported in near-real-time. During quiet times, the Dst value is between +20 and $-20 \mathrm{nT}$. Based on a geomagnetic storm's strength, it can be classified as a moderate storm for Dst between -50 and $-100 \mathrm{nT}$, intense for Dst between - 100 and $-200 \mathrm{nT}$, and severe or super-storm for Dst less than - $200 \mathrm{nT}$ [15].

In the proposed work, an attempt is made to see if TEC can be used to study and understand the impact of space weather phenomena. This study of the dependency of TEC on AE and Dst indices can be helpful to understand the impact of space weather phenomena on the satellite-based system. The advantage of using TEC is its high temporal resolution as compared to other indices used for measuring geomagnetic storms like Dst and $\mathrm{AE}$, which are available at 1-h intervals, or Kp, which is available at 3-h intervals. Furthermore, the equatorial ionosphere is characterized by large ionospheric gradients (even within $5^{\circ} \mathrm{X} 5^{\circ}$ latitude and longitude). The deviations and perturbations in the TEC at different latitudes due to geomagnetic storms are also different. Thus, investigating the causality between the geomagnetic storm and TEC at the regional level can be useful in improving the existing methods used for correcting positional errors. This can be achieved with the high spatial resolution regional TEC data available from the GNSS receivers which have a wide global coverage. As causal inferences can result in the selection of physical quantities which are more informative, hence, the proposed study can be further combined with data-driven models for improved estimation of positional forecasting errors in the propagating signal. 


\section{Granger causality test}

Causality refers to the dependency between variables and is different from correlation. Although there is a well-known correlation between variation in TEC during the occurrence of geomagnetic storms and substorms, there is no clear, direct cause and effect relation between them which can be modeled to forecast TEC.

Several attempts to forecast TEC using geomagnetic disturbances (in terms of both geomagnetic indices $\mathrm{AE}$ and Dst measurements) during magnetic storms and substorms have been developed using Artificial Neural Networks and linear or nonlinear regression models $[16,17]$. However, most of these models are based on using a large historical dataset of these physical quantities. Many feature selection methods have also been combined with these models to identify the most relevant physical quantity. However, there is little work done in the area to identify the most informative physical quantities. Most of the studies are based on the correlation between the physical quantities which may not be very indicative due to the nonlinear and abrupt nature of these variations [18].

In a stochastic system, Granger causality between the variables can be established if it is possible for variable $X_{t}$ to cause $Y_{t+1}$ or for $Y_{t}$ to cause $X_{t+1}$ where $t$ is the time variable [19]. This paper investigates the causality between the variables-deviation in TEC, Dst, and AE. The Granger causality test or G test method proposed by the Nobel Economics Prize recipient Clive W. J. Granger is used to analyze the causality between the variables.

For a time series, the Granger causality is said to exist between two variables, $X$ and $Y$, if variable $X$ can help explain $Y$ 's future values, considering both time series are stationary or steady. Therefore, before conducting the Granger causality test, it is necessary to conduct a unit root test of the time series' stationarity, which ensures the stationarity of the time series. The Augmented Dickey-Fuller test (ADF test) is generally used to conduct this unit root test of stationarity of the series. The Granger causality is sensitive to the lag period, and under different lag periods, completely different test results can be obtained if a precondition of stationarity is not satisfied. Thus, a series of pretests must be performed on the data before the $\mathrm{G}$ test.

In the present study, the deviation in TEC denoted by DTEC is taken as $Y$ or the dependent variable, and Dst or AE are explanatory variables $X_{1}$ and $X_{2}$. The causality test is performed to check if AE/Dst can cause deviation in TEC. Hence, if $X_{1} / X_{2}$ does not help predict variable $Y$, which is DTEC, then $X_{1} / X_{2}$ is not the cause for the deviation in TEC. On the contrary, if the Dst or AE is the cause for DTEC, then AE and Dst should be able to predict the variable DTEC. A statistical hypothesis is tested to establish the causality. This can be explained with a mathematical formulation of the test based on vector autoregression (VAR) modeling of stochastic processes based on the past value of two variables $Y$ and $X$ [20]. The regression equation for two variables can be expressed as shown below:

$$
\begin{aligned}
& \mathrm{Y}(\mathrm{t})=\sum_{j=1}^{\mathrm{p}} A_{11, j} \mathrm{Y}(\mathrm{t}-\mathrm{j})+\sum_{\mathrm{j}=1}^{\mathrm{p}} A_{12, j} \mathrm{X} 1(\mathrm{t}-\mathrm{j})+\sum_{j=1}^{\mathrm{p}} A_{13, j} \mathrm{X} 2(\mathrm{t}-\mathrm{j})+E_{1}(\mathrm{t}) \\
& \mathrm{X} 1(\mathrm{t})=\sum_{j=1}^{\mathrm{p}} A_{21, j} \mathrm{Y}(\mathrm{t}-\mathrm{j})+\sum_{j=1}^{\mathrm{p}} A_{22, j} \mathrm{X} 1(\mathrm{t}-\mathrm{j})+\sum_{j=1}^{\mathrm{p}} A_{23, j} \mathrm{X} 2(\mathrm{t}-\mathrm{j})+E_{2}(\mathrm{t}) \\
& \mathrm{X} 2(t)=\sum_{\mathrm{j}=1}^{\mathrm{p}} A_{31, j} \mathrm{Y}(\mathrm{t}-\mathrm{j})+\sum_{\mathrm{j}=1}^{\mathrm{p}} A_{32, j} \mathrm{X} 1(\mathrm{t}-\mathrm{j})+\sum_{\mathrm{j}=1}^{\mathrm{p}} A_{33, j} \mathrm{X} 2(\mathrm{t}-\mathrm{j})+\mathrm{E}_{3}(\mathrm{t})
\end{aligned}
$$


where $p$ is the maximum number of lagged observations; the coefficients of the model are the contributions of each lagged observation to the predicted values of $X_{1}(t), X_{2}(t)$, and $Y(t)$; and $E_{1}, E_{2}$, and $E_{3}$ are residuals (prediction errors) for each time series. If the variance of $E_{1}$ (or $E_{2} / E_{3}$ ) is reduced by the inclusion of the $Y$ (or $X$ ) terms in the equation, then it is said that $Y$ (or $X$ ) Granger-(G)-causes $X$ (or $Y$ ). In other words, $Y$ Gcauses $X$ if the coefficients in $A i j$ are significantly different from zero. This is tested by performing a $t$-test or chi-squared test of the null hypothesis that $A i j=0$, given assumptions of covariance stationarity on $X$ and $Y$.

\section{Cointegration}

The cointegration test is done to establish the presence of a statistically significant connection between two or more time series. It is seen that if two variables are cointegrated, then there exists causality between variables in at least one direction [21]. Thus, a cointegration test can be viewed as an indirect test of long-run dependence. It occurs when two or more non-stationary time series have a long-run equilibrium and move together so that their linear combination of variables results in a stationary time series. There is a linear combination of the variables with an order of integration less than that of the individual series. In this context, cointegration can help understand if there is a long-run equilibrium between deviation in TEC during the disturbed condition and Dst/AE. The cointegration test establishes a stationary linear combination of time series that are not themselves stationary.

Thus, the cointegration test indicates a long-run equilibrium relationship between variables, while the Granger causality test indicates a unidirectional causality. The results of cointegration determine the type of regression model to be implemented for the causality test. The regression results with non-stationary variables can be spurious if the variables are non-stationary and cointegrated. Furthermore, the regression with the first differenced variables is for short-run relationship; hence, it cannot capture the long-run information. In such cases, the causality is investigated through vector error correction model (VECM). It is an extension of the VAR model to include cointegrated variables that balance the short-term dynamics of a process with the long-term dependencies. The VECM expresses the long-run dynamics of the process including error correction terms that measure the deviation from the stationary mean at $(t-1)$ time. Thus, linear Granger causality on VAR can be applied only to time series that are stationary. If data are not stationary and not cointegrated, then the VAR can fit to the differenced time series. For a cointegrated non-stationary time series, with a long-term equilibrium relationship, the time series have to be fitted with the VECM model to evaluate the short-run properties of the cointegrated time series.

In this paper, three variables namely deviation in TEC, Dst, and AE are investigated under different storm conditions and for two different locations in the equatorial region. The primary aim is to identify the extent of causality and identify causal variables that can cause a state transition. As per the Granger causality principles [22], forecasting is related to identifying causal variables responsible for state transitions. Therefore, Granger causality inferences between variables can be combined with forecasting and can improve forecasting. 


\section{Methods}

The data used for the study is from the year 2015 which is the descending phase of the 24th solar cycle. The year 2015 is characterized by 56 geomagnetic storms, of which the storm on March 17, 2015, was the most severe one (St. Patrick's storm) of the solar cycle [23]. This storm had major adverse effects on communication and navigation systems on and above the Earth. The present study is conducted with thirty geomagnetic storms. In this paper, twelve geomagnetic storms are presented, which is used to verify the causal effect of geomagnetic indices on ionospheric TEC measured at two different GPS stations at Bangalore and Hyderabad. The geographic and geomagnetic coordinates (latitudes and longitudes) of the GPS stations are given in Table 1.

The storms considered for this study are of different intensities and of different types and origins (recurrent and sporadic). The details of the storm durations, storm type, geomagnetic indices (Dst and AE), and TEC characteristics are listed in Table 2. The maximum TEC values for all storm days are higher than the quiet day maximum TEC value. Furthermore, the maximum value of TEC is observed to be higher at Hyderabad due to the crest formation around noon time.

\section{Data preparation}

For this study, three parameters namely deviation in TEC denoted by "DTEC" and the geomagnetic storm indices "Dst" and AE" are used. Both Dst and AE are available at 1$\mathrm{h}$ time interval and DTEC is available at 2.5-minute interval. The DTEC is calculated from the vertical total electron content (VTEC) for which the calculation is shown in the next section. The descending phase of the twenty-fourth cycle is chosen and the VTEC data of geomagnetic storm days occurring in this period is considered for this study. The storm days are selected based on the Dst index.

\section{Calculation of VTEC}

The VTEC is the vertical total electron content and is computed from the receiver independent exchange (RINEX) observation files of the International GNSS Service (IGS) receiver stations at Bangalore (IISC) and Hyderabad (HYDE). The data is processed using GPS-TEC online application software, developed by Ionolab [24]. The desired TEC is the combination of calculated TEC and receiver and satellite biases in TEC units. The TEC is computed using the standard procedure to compute the absolute total electron content on the slant ray path (STEC) from the satellite to the receiver and is calculated from the difference of pseudo ranges $P 1$ and $P 2$ at $L 1$ and $L 2$ frequencies respectively.

The computed slant TEC is projected to the local zenith direction to obtain the vertical TEC through a mapping function, $M(E, h)$, assuming a thin shell model of the ionosphere. The receiver and satellite biases are also added to compute the VTEC values. The VTEC value is computed as shown in Eq. 5:

Table 1 Locational coordinates of GPS stations

\begin{tabular}{|c|c|c|c|c|}
\hline Location & Geographic latitude & Geographic longitude & Geomagnetic latitude & Geomagnetic longitude \\
\hline Bangalore & $13.02^{\circ} \mathrm{N}$ & $77.57^{\circ} \mathrm{E}$ & $4.49^{\circ} \mathrm{N}$ & $150.93^{\circ} \mathrm{E}$ \\
\hline Hyderabad & $17.41^{\circ} \mathrm{N}$ & $78.55^{\circ} \mathrm{E}$ & $8.77^{\circ} \mathrm{N}$ & $152.24^{\circ} \mathrm{E}$ \\
\hline
\end{tabular}




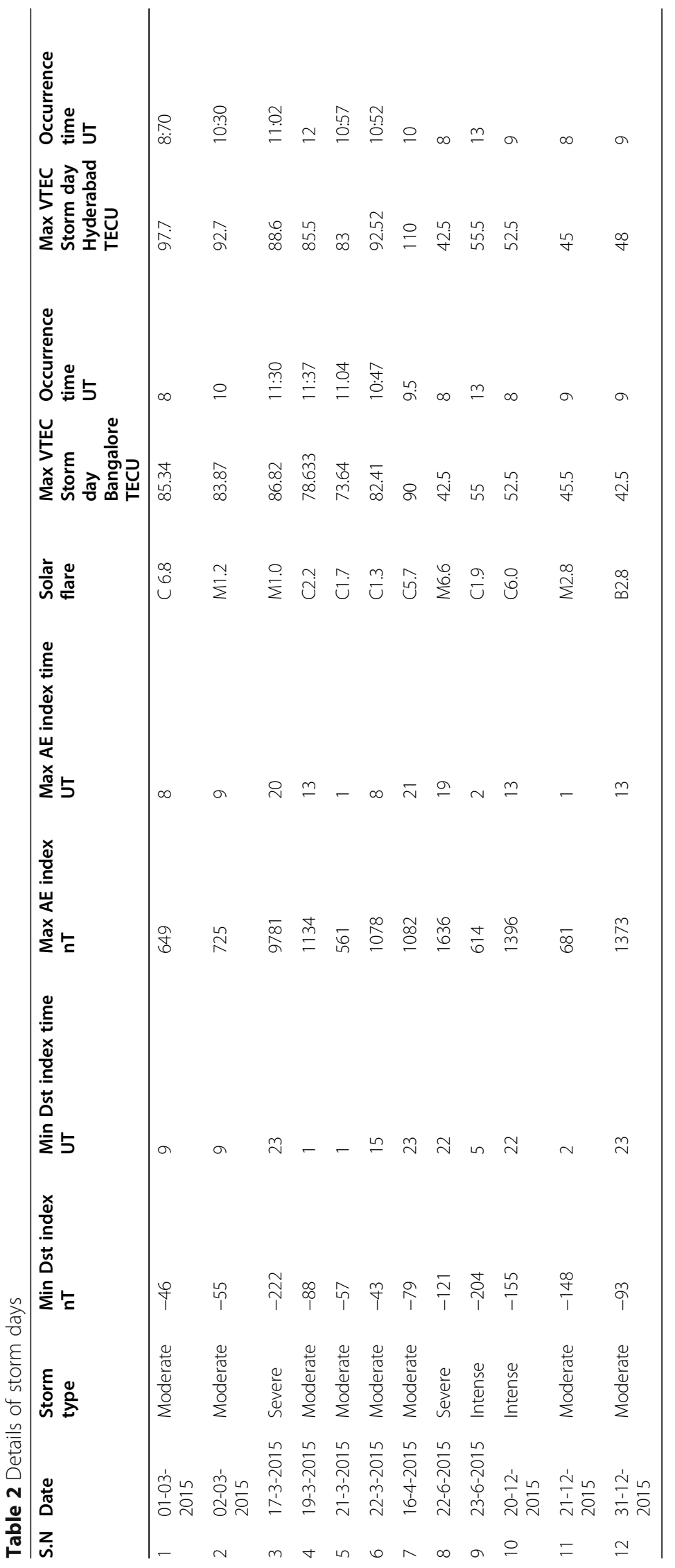




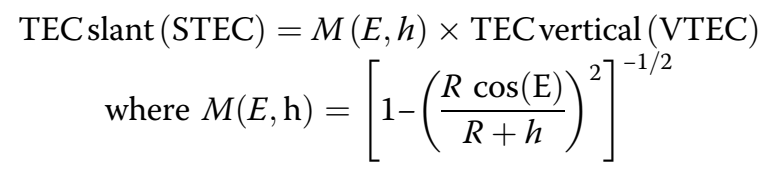

In the above formula, $R$ is the radius of the Earth, $E$ is the elevation angle, and $h$ is the height of the ionospheric pierce point.

\section{Calculation of deviation in TEC (DTEC)}

The DTEC is the deviation in TEC on a geomagnetic storm day w.r.t. the TEC on a quiet day. For this calculation, the quietest day of the month is selected to be used as the reference TEC pattern for that month. Monthly selection is done to take care of seasonal variations in TEC. The quiet day is selected based on the Dst and Kp indices. The quiet days selected for every month have low solar and geomagnetic activities such that Dst variation does not exceed 5 to $10 \mathrm{nT}$ over the entire day and the absolute value is also within -15 to $15 \mathrm{nT}$. The DTEC is computed as a deviation in TEC, as shown in Eq. 6

$$
\text { DTEC }=\text { TEC storm }- \text { TEC quiet }
$$

The DTEC is the measure of deviation in TEC caused due to disturbed geomagnetic storm conditions over the entire day. Figure 1 shows the comparison of the VTEC variation pattern for a quiet day on March 10, 2015, and a moderate geomagnetic storm day on March 2, 2015, at Hyderabad. Similarly, Fig. 2 shows the variation for Bangalore station for a quiet day on March 10, 2015, and a geomagnetic storm day on March 2, 2015. Figures 3 and 4 show the plot of DTEC for March 2, 2015, for both Hyderabad and Bangalore. In the equatorial region, the TEC pattern shows latitudinal variation which can be seen in Figs. 1 and 2. Hence, DTEC is also different for both the latitudes. The geomagnetic storm that occurred on March 17, 2015, is considered the most intense storm of the solar cycle. Hence, the TEC pattern also shows a steep rise in TEC around 5 UTC. This can be seen in Figs. 5 and 6 which represent the comparison of variation pattern between quiet day (10-3-2015) and severe geomagnetic storm day on March 17, 2015, for Hyderabad and Bangalore stations, respectively. Figures 7 and 8 show the DTEC for March 17, 2015, for Hyderabad and Bangalore, respectively, which is different from the DTEC on March 2, 2015. Major variation in the TEC pattern is generally seen on severe storm days while the minor variation pattern is observed for moderate storm days.

The figures clearly indicate that the deviation pattern also varies with latitude. The DTEC is more abrupt during days having the main phase of intense/severe storms (173-2015). This is further verified from Figs. 9 and 10 which show deviation in TEC for another severe storm day that occurred June 22, 2015. Figures 11 and 12 are the DTEC variation on a moderate storm day, Dec 31, 2015, where rapid variations of smaller magnitudes are seen.

\section{Data for Dst and AE indices}

The data for the DST index and AE index are downloaded from data centers for geomagnetism, Kyoto website (http://wdc.kugi.kyoto-u.ac.jp). Both indices describe the 

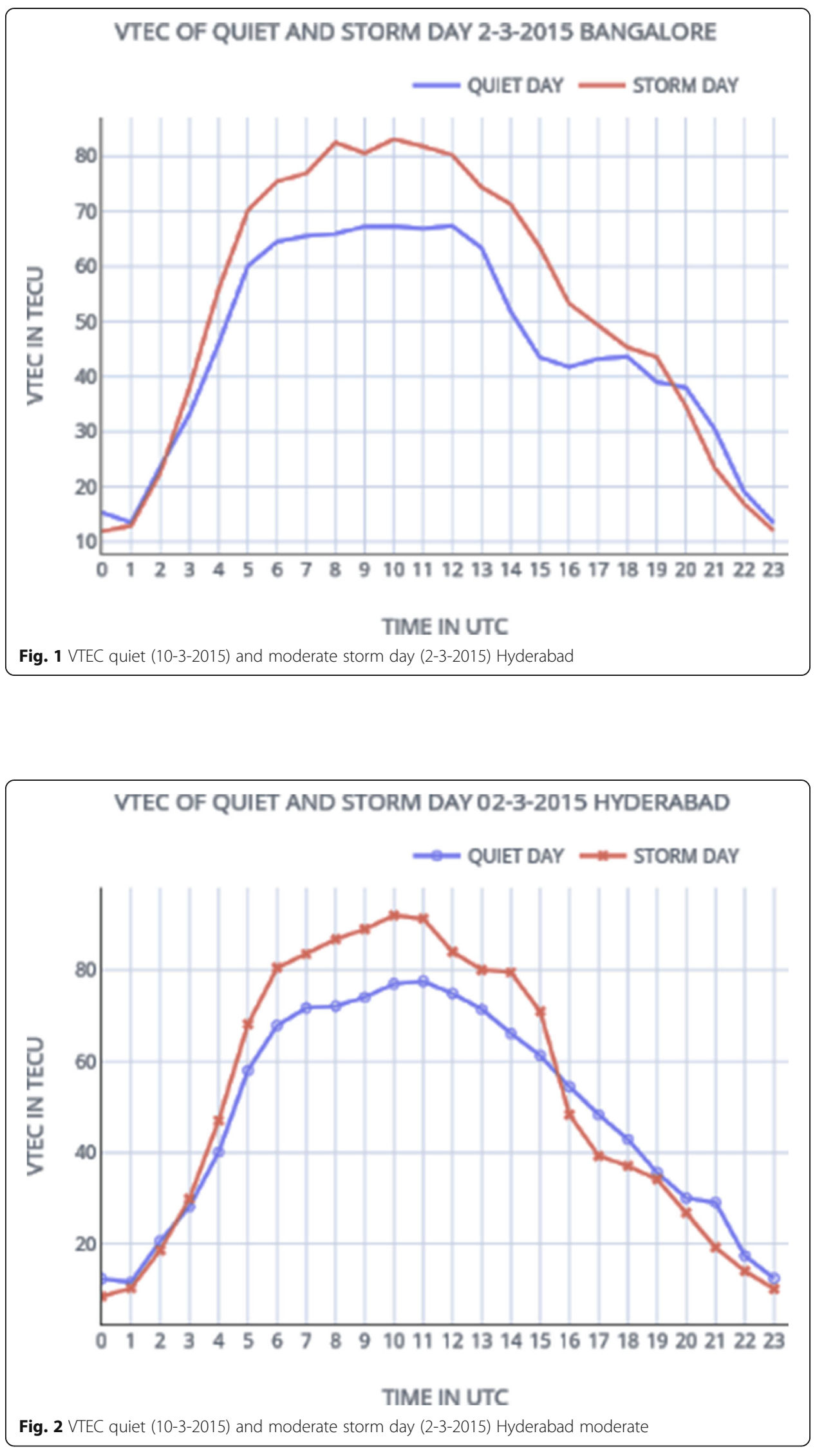


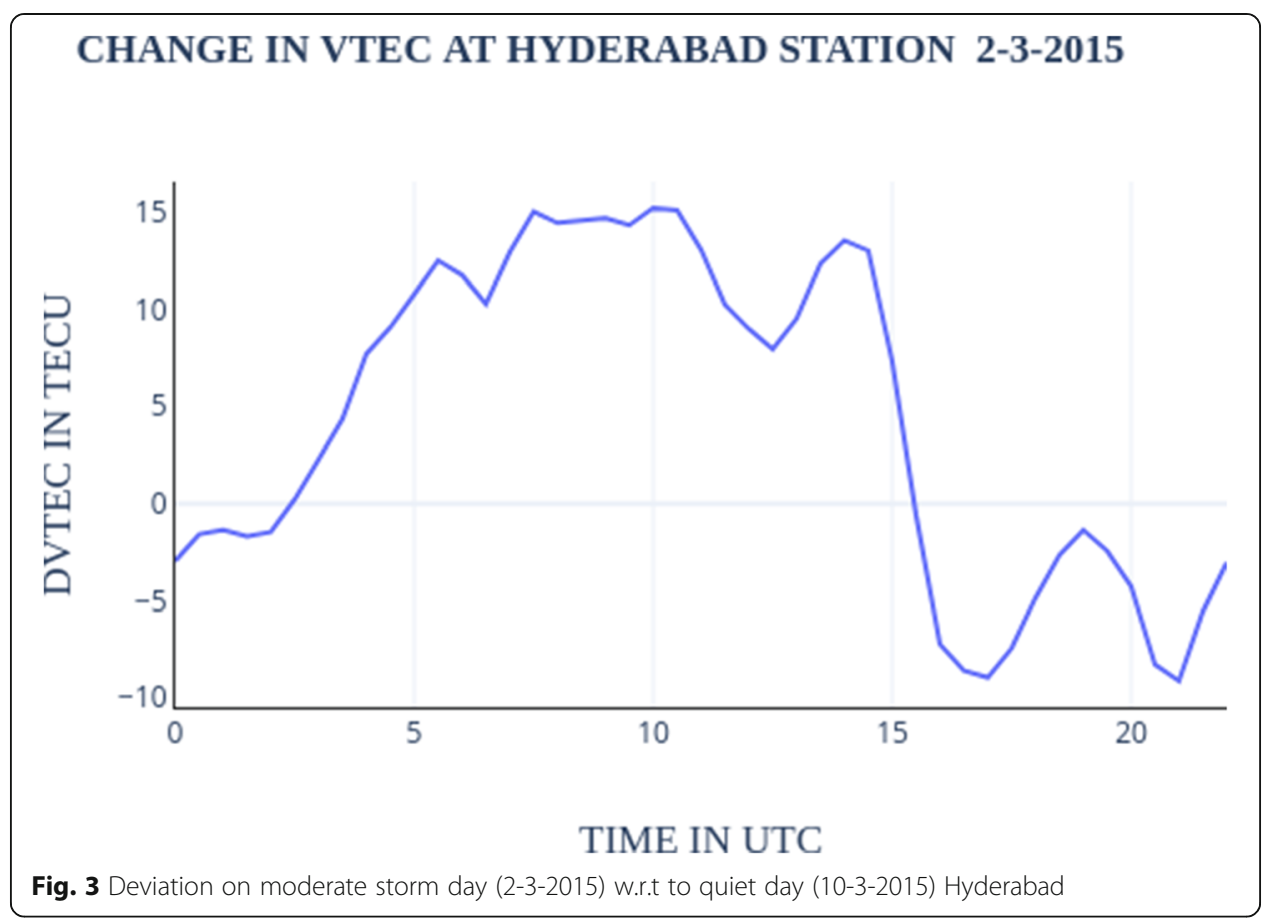

intensity of the storm. The variation pattern of Dst is also useful in finding the phase of the storm. The type of the storm, sudden or recurrent, can also be deduced from the Dst variation pattern.

A geomagnetic storm is defined by changes in the Dst index. Dst is computed once per hour and reported in near-real-time. During quiet times, Dst is between +20 and 20 nano-Tesla (nT). Figure 13 shows the Dst variation on a quiet day 10-3-2015 and

\section{CHANGE IN VTEC AT BANGALORE STATION 2-3-2015}

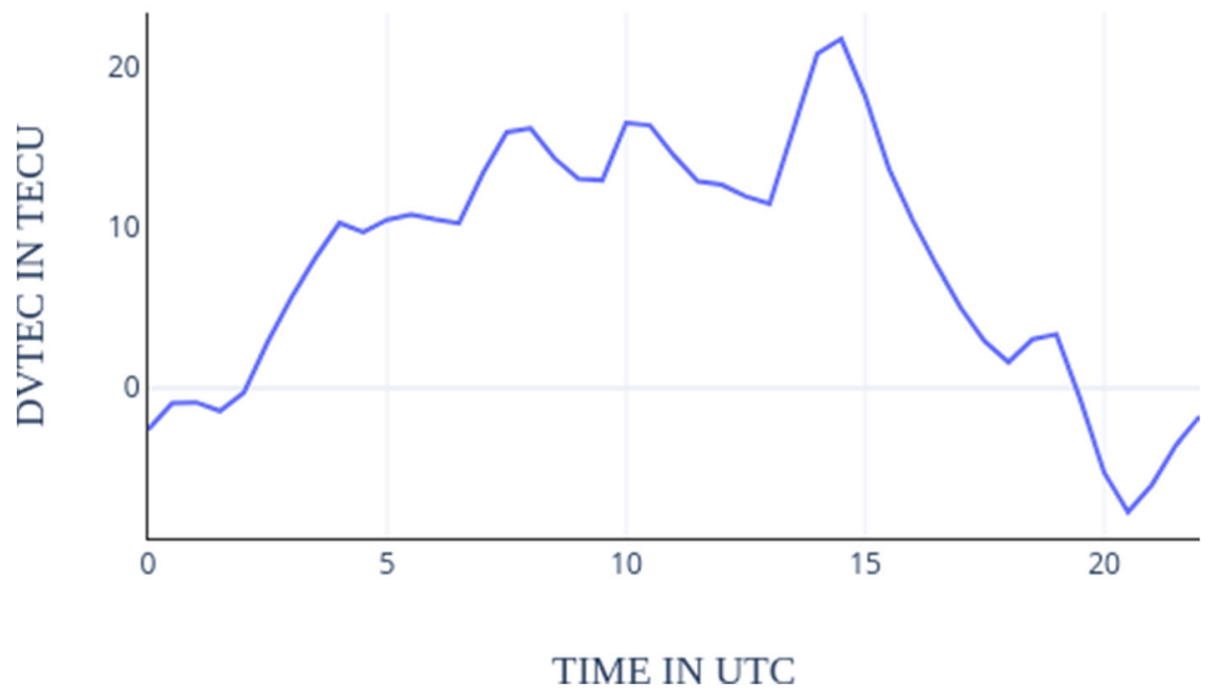

Fig. 4 Deviation on moderate storm day (2-3-2015) w.r.t to quiet day (10-3-2015) Bangalore 

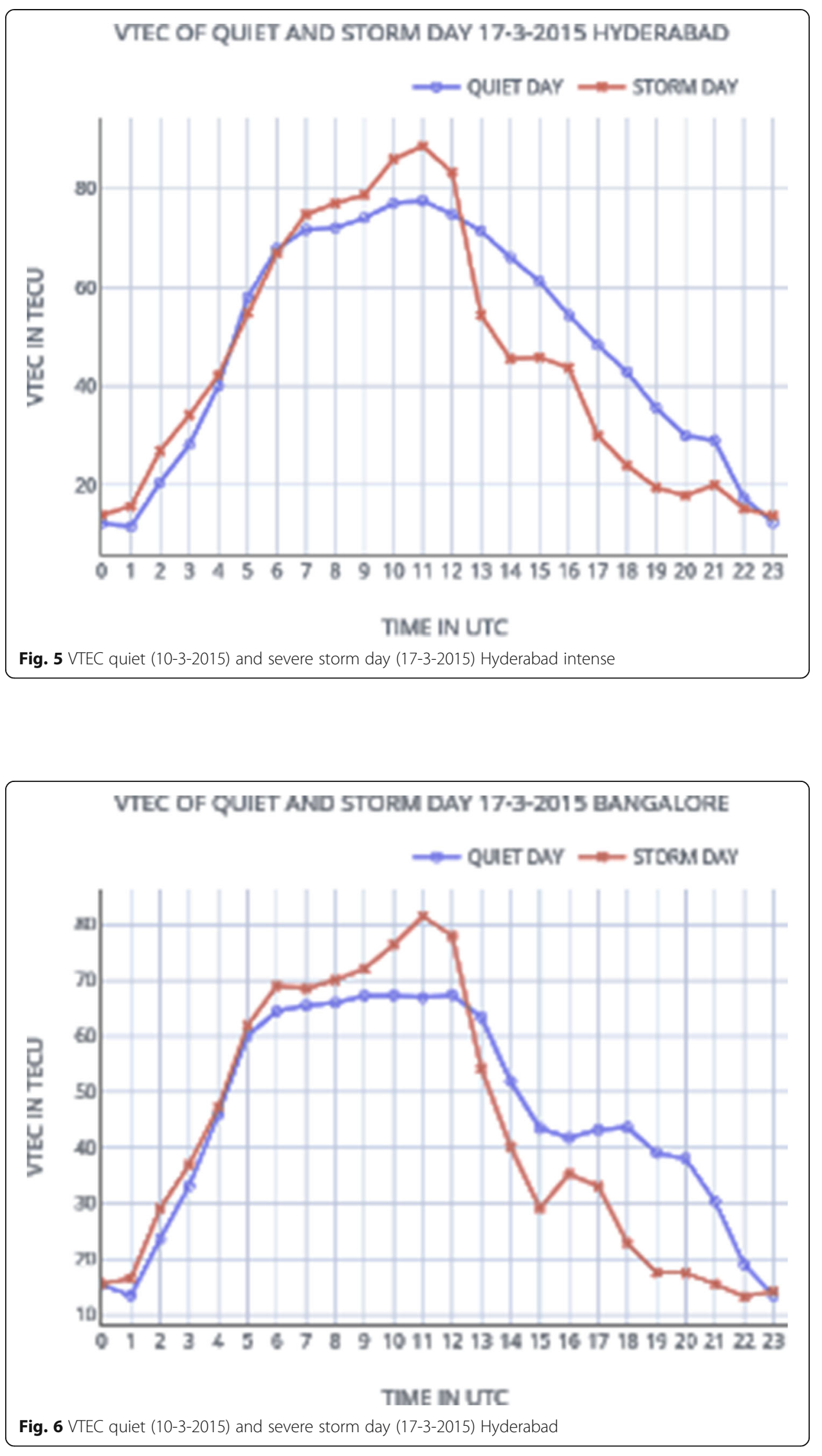


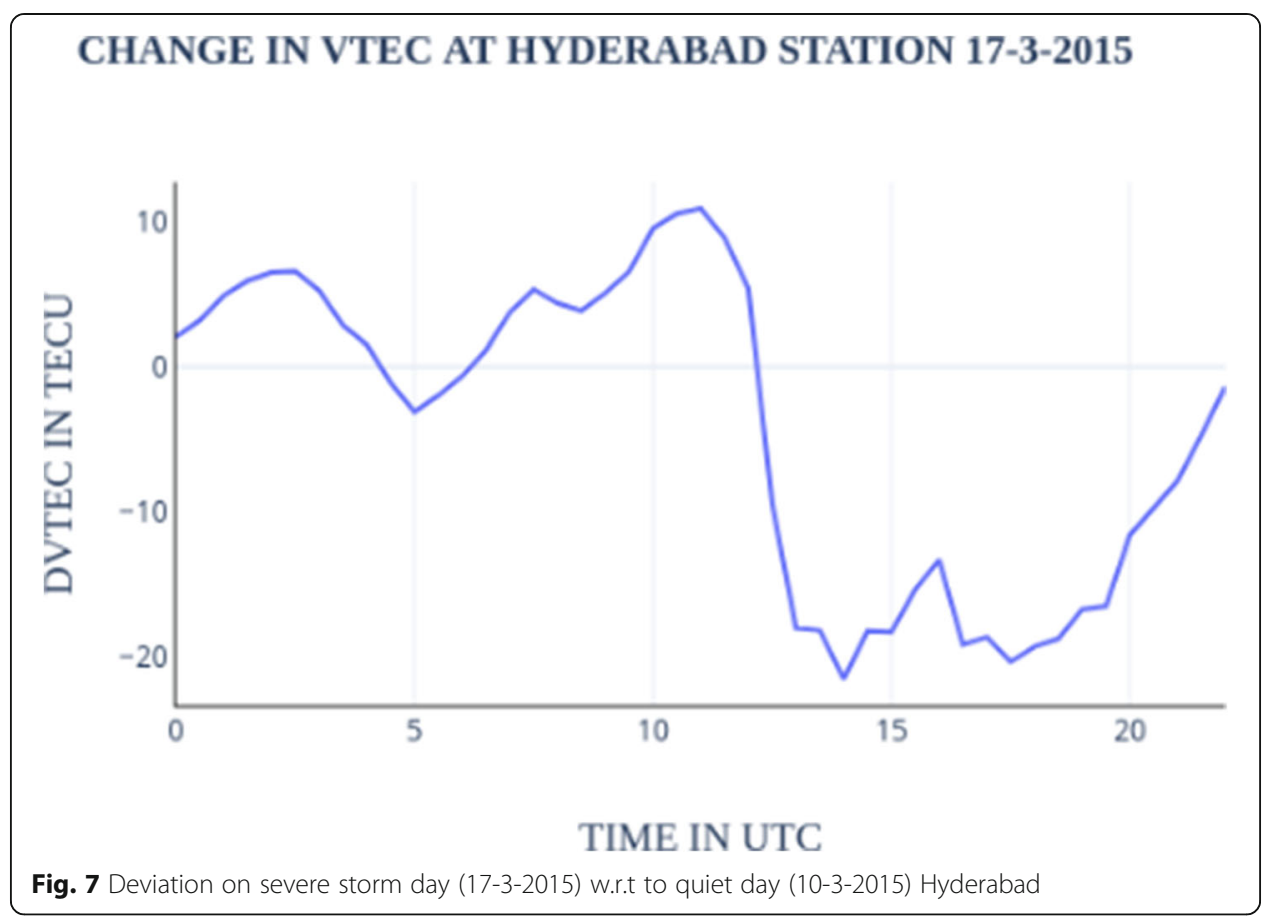

19-1-2015. These days have also been used as reference days in this study. The variation is between 1 and $10 \mathrm{nT}$ on 10-3-2015 and between -10 and $10 \mathrm{nT}$ on 19-1-2015.

Most of the geomagnetic storms have three phases: initial, main, and recovery. The initial phase is characterized by an increase in Dst by 20 to $50 \mathrm{nT}$ in a short time. The initial phase is also referred to as a storm sudden commencement (SSC). This is followed by the main phase characterized by Dst decreasing to less than $-50 \mathrm{nT}$. The

\section{CHANGE IN VTEC AT BANGALORE STATION 17-3-2015}

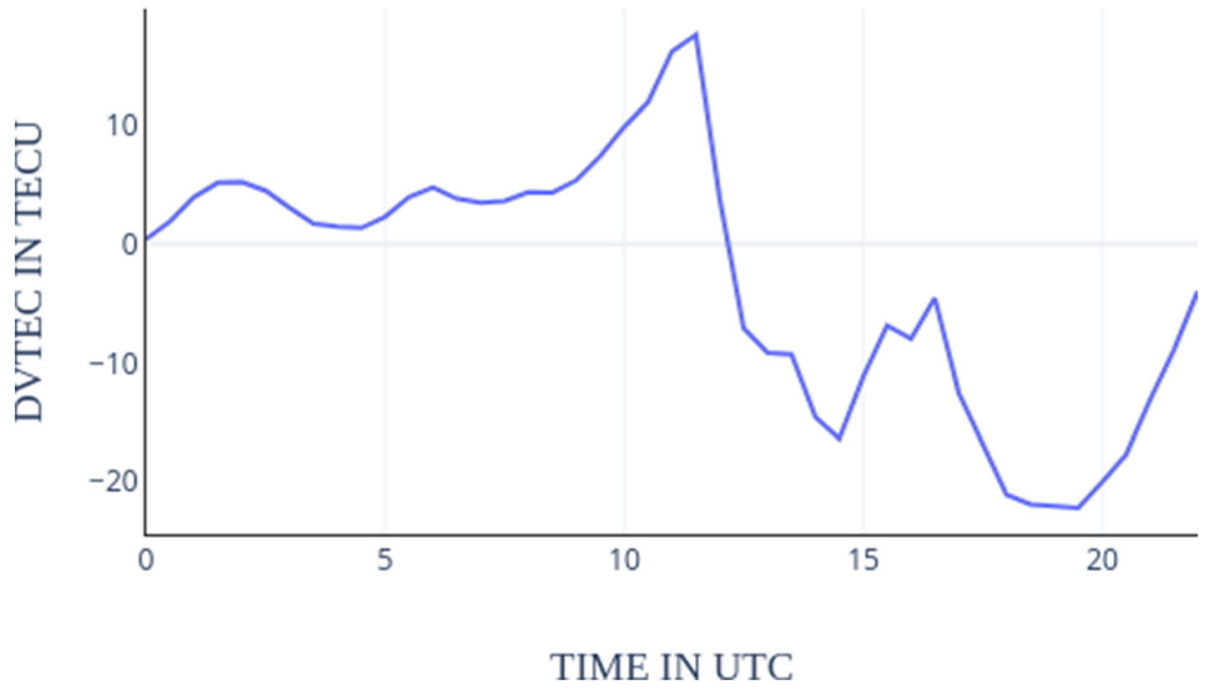

Fig. 8 Deviation on severe storm day (17-3-2015) w.r.t to quiet day (10-3-2015) Bangalore 


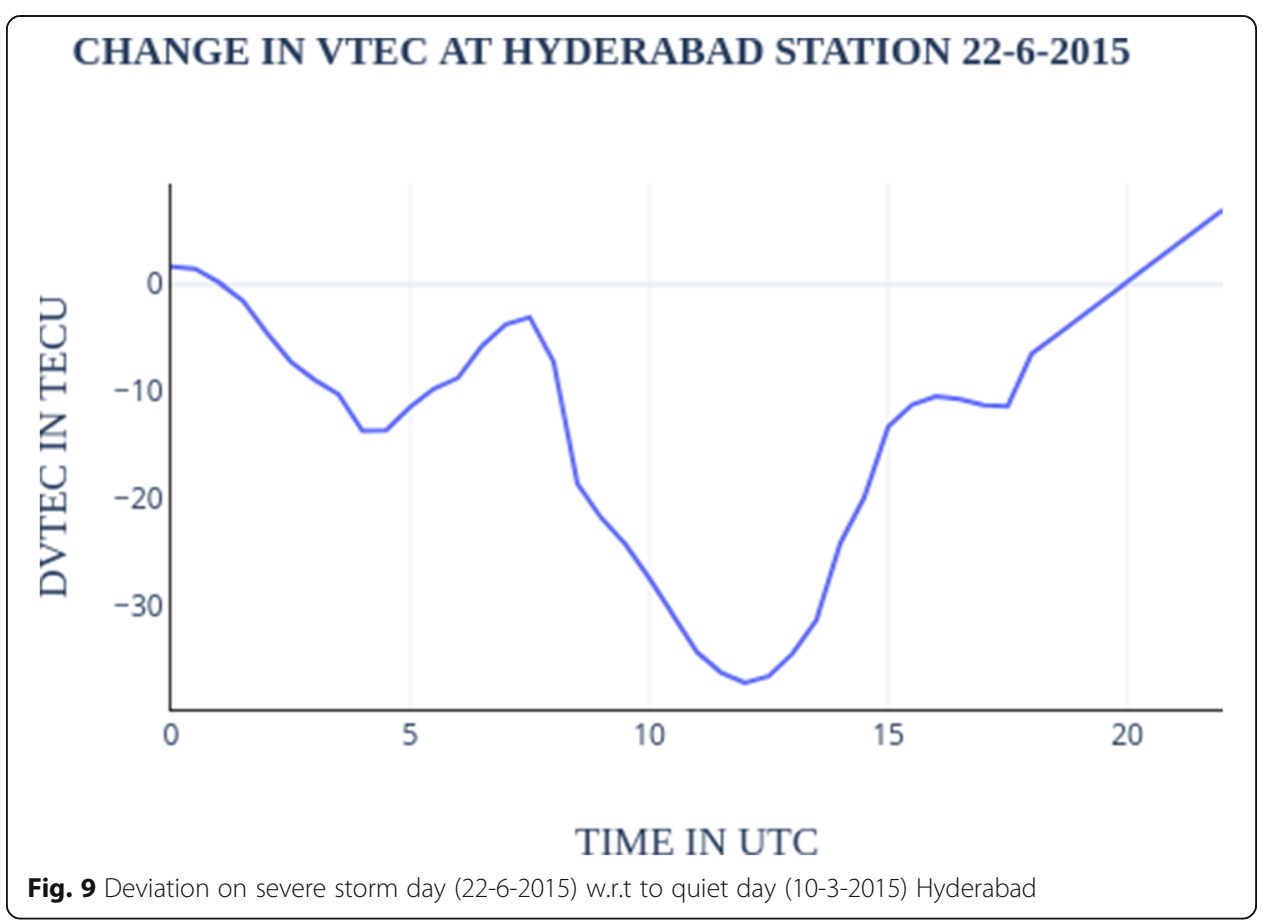

minimum value during a storm can range from -50 to $-600 \mathrm{nT}$ in extreme cases. The duration of the main phase is typically $2-8 \mathrm{~h}$. The recovery phase is when Dst changes back from its minimum value to its quiet time value. The recovery phase may range from $8 \mathrm{~h}$ to 7 days. However, not all geomagnetic storms have an initial phase and not all sudden increases are followed by a geomagnetic storm. Figure 14 shows the Dst variation of severe geomagnetic storm day on 17-3-2015 and a moderate storm day on

\section{CHANGE IN VTEC AT BANGALORE STATION 22-6-2015}

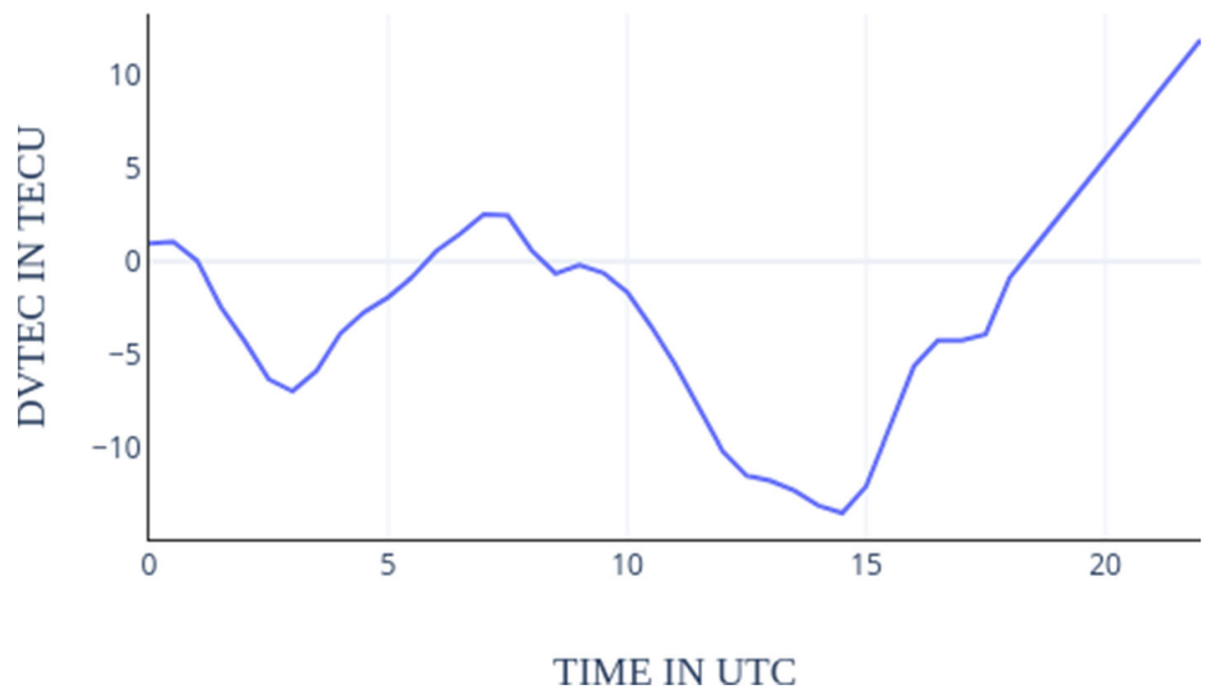

Fig. 10 Deviation on severe storm day (22-6-2015) w.r.t to quiet day (10-3-2015) Bangalore 


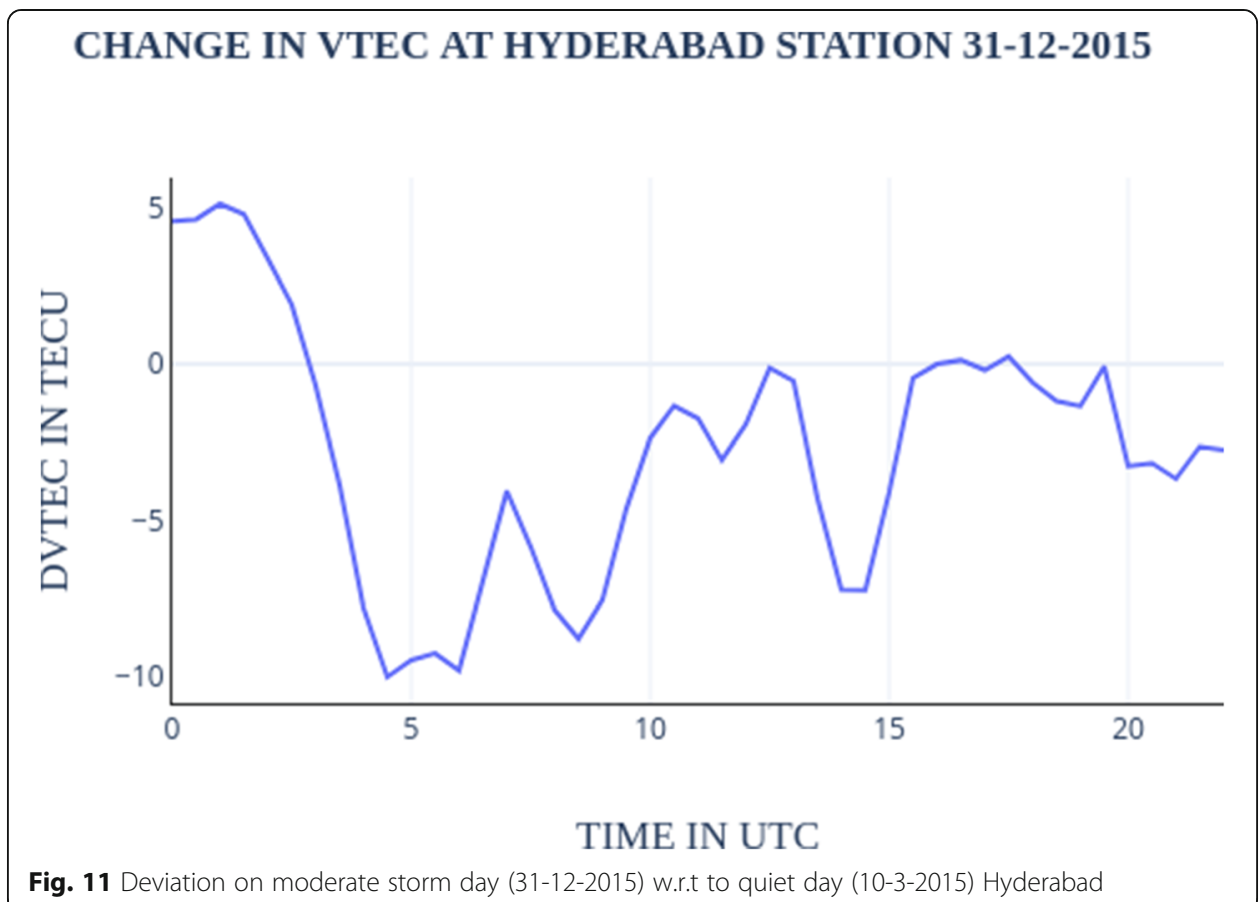

31-12-2015 considered during this study. The Dst variation on 17-3-2015 indicates the rising Dst in the initial phase and Dst reaching its minimum $(-220 \mathrm{nT})$ in the main phase of the storm. The moderate storms are many times recurrent and periodic in nature with a gradual decrease in Dst. The Dst pattern is more predictable. Sometimes, substorms are triggered during the recovery phase of intense storms.

CHANGE IN VTEC AT BANGALORE STATION 31-12-2015

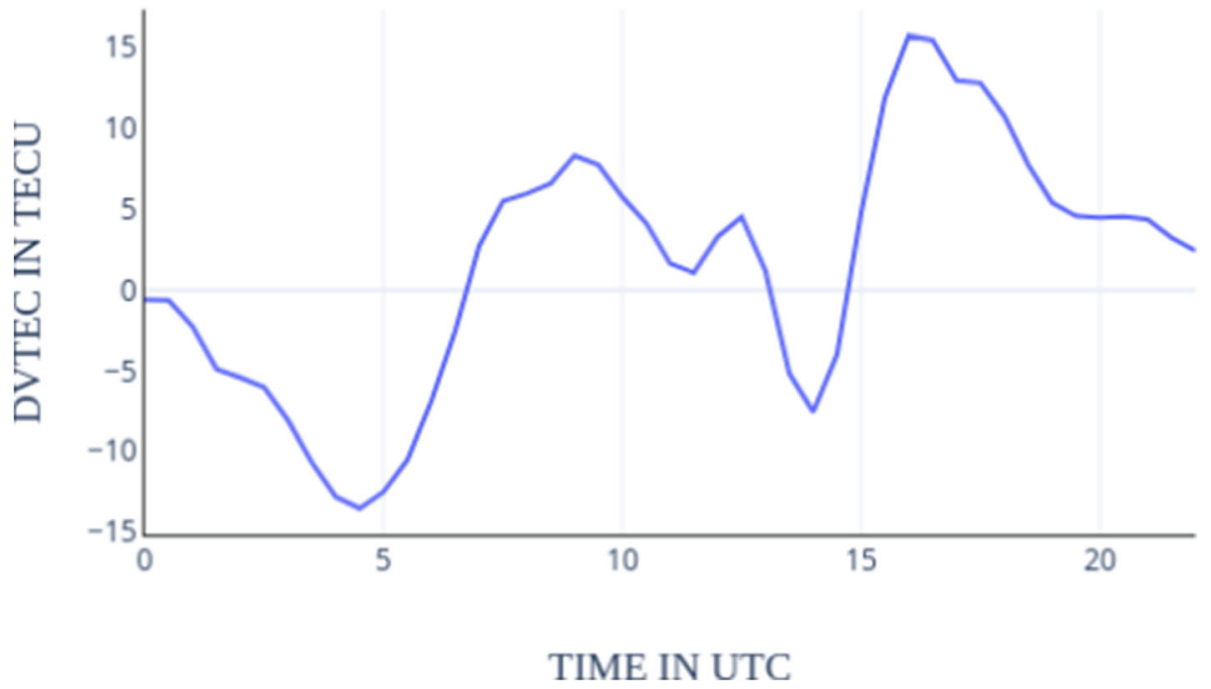

Fig. 12 Deviation on moderate storm day (31-12-2015) w.r.t to quiet day (10-3-2015) Bangalore 


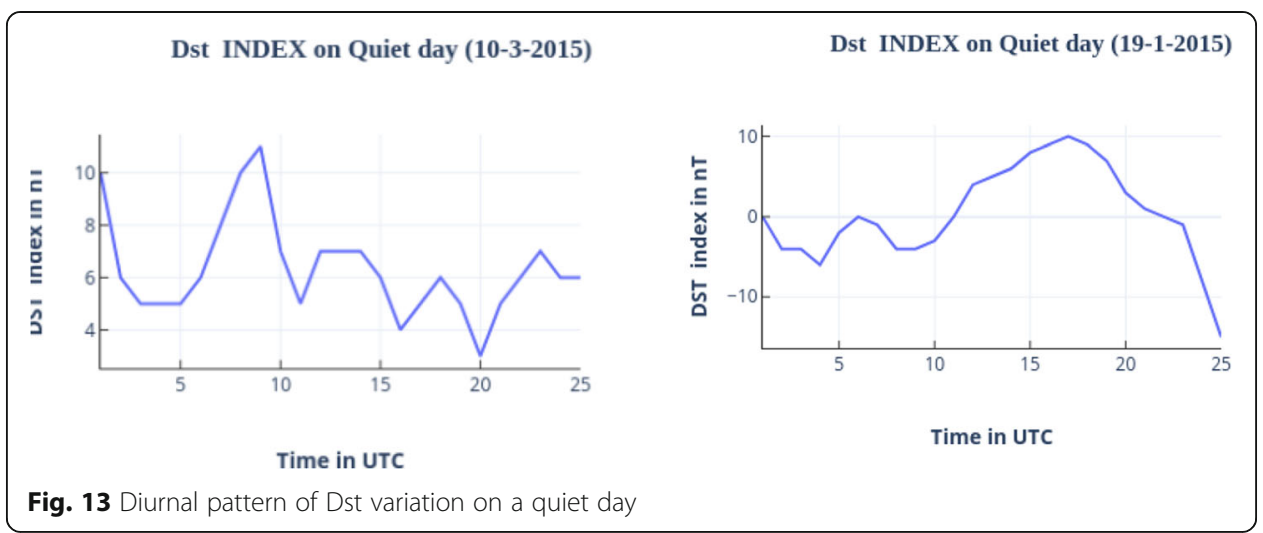

The AE index represents the auroral zone magnetic activity produced by enhanced ionospheric currents flowing below and within the auroral oval. The equatorward expansion of auroral electrojet influences the TEC in the low-latitude ionosphere. They have been useful in studying the magnetic substorms. The enhancement in $\mathrm{AE}$ can be seen on days with high geomagnetic activity. Figure 15 shows the AE index for quiet and storm days. The quiet days on 10-3-2015 show two peaks of 200nT and for most of the day the value is not more than $50 \mathrm{nT}$. The AE index ranges between 50 and 200nT on 19-1-2015. Two storm days one severe (17-3-2015) and one moderate (3112-2015) are shown in Fig. 15. On both days, the TEC is enhanced to around 1500nT and for most of the day, it is more than 500nT.

\section{Data scaling}

All the geomagnetic indices and DTEC are normalized using the Min-Max scaler method. The Min-Max scaler is chosen as it preserves the original distribution's shape and does not change the meaning of the information embedded in the original data.

\section{Results and discussion}

In this section, the results for twelve different geomagnetic storms of different origins and types are presented. The year 2015 had a total of 56 storms out of which 52 were of low or moderate intensity, 2 were intense, and 2 were severe. In this paper, the test results for two severe storms and two intense storms and 8 moderate storms are presented. The tests have been conducted for thirty storm days at both Bangalore and

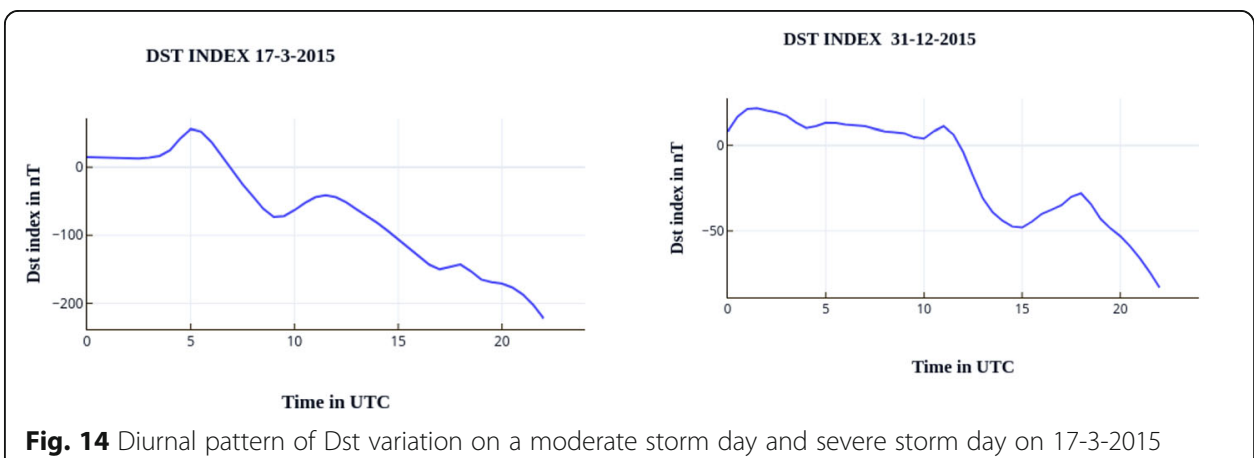




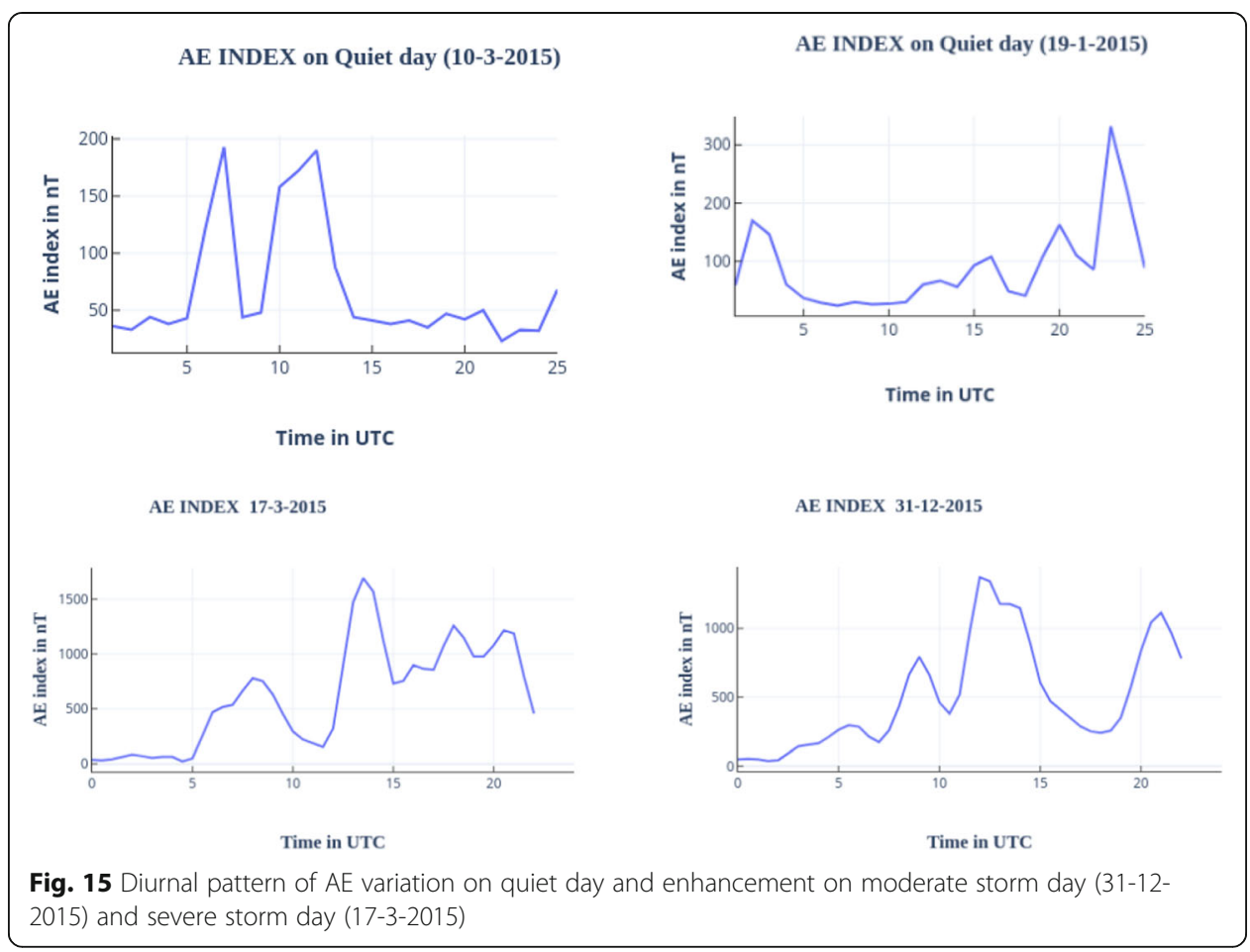

Hyderabad stations as TEC data was not available for some of the disturbed days. Three tests namely the Augmented Dickey-Fuller Test, Granger causality test, and cointegration test are carried out. All the tests are performed on normalized data. First, the stationarity of raw data is tested. The stationarity is tested using the Augmented DickeyFuller Test (ADF test). The Granger causality test is performed on the stationary data. The causality between the variables and the direction of the causality is tested using the Granger causality test. The long-term equilibrium relationships between variables are tested using the cointegration test. The detailed observations are presented below.

\section{Stationary test of variables}

All the three time-series data are first tested for trend and stationarity. Differencing technique is used for making the data stationary. The stationarity is tested after every differencing. The differenced data's stationarity is tested after single and double (if required) differencing using the Augmented Dickey-Fuller Test (ADF test). The test uses the null hypothesis: "Data has a unit root and is non-stationary" is tested. The test is performed for different lag values with a 0.05 significance value. The $p$ value is used to decide if there is any evidence to reject the null hypothesis. This test is repeated for all the data variables.

\section{Cointegration test}

Johansen cointegration test is performed on data to establish the presence of a statistically significant relationship between the time series. The Johansen method is based on the relationship between the rank of the matrix $\Pi$ and the size of its eigenvalues. The rank of the matrix $\Pi$ determines the long-term dynamics. If $\Pi$ has full rank, the process 
$Y_{t}$ is stationary in mean. If the rank of $\Pi$ is zero, then the error correction term disappears, and the system is stationary in differences (the VAR model in differences can be used). If the rank of $\Pi$ is $r$ (within $(0, K)$ ), then there are $r$ independent cointegrating relations among the variables in $Y_{t}$. For a given $r$, the maximum likelihood estimator of $\beta$ defines the combination of $Y_{t-1}$ that yields the $r$ largest canonical correlations of $\Delta Y_{t}$ with $Y_{t-1}$.

The null hypothesis "There are no cointegrating equations" is tested for a 95\% confidence level. If the trace statistics is greater than the critical value, then the null hypothesis is rejected, establishing linear relation between the variables. Hence, for cointegration to exist, the null hypothesis must be rejected. The cointegration test is carried out between DTEC, Dst, and AE for all storm days. The cointegration is true for most of the cases, and hence, there exists a long-run dependency between the variables and DTEC, AE, and Dst.

\section{Results of the cointegration test for Bangalore}

To test the null hypothesis that the variables are not cointegrated, trace and eigenvalue statistics are carried out. For most of the cases, null hypotheses are rejected for both eigen and trace tests. All tests are conducted with 5\% critical value. Since the maximum eigenvalue and trace test statistics values are higher than $5 \%$ critical values, the alternative of one or more cointegrating vectors is accepted.

Johansen cointegration with the hypothesis of the reduced rank of a regression coefficient matrix, estimated consistently from vector regression equations, is also tested. Here, the maximum eigenvalue statistic and the trace statistic test the number of cointegrating relations between variables. The trace test is a joint test where the null hypothesis is "number of cointegrating vectors is less than or equal to $r$," against a general alternative that "there are more than $r$ vectors," whereas the maximum eigenvalue test conducts separate tests on the individual eigenvalues, where the null hypothesis is that the "number of cointegrating vectors is $r$," against an alternative of $(r+1)$.

Table 3 shows the cointegration results for twelve geomagnetic storm days for the year 2015. The test is done pairwise between DTEC and Dst and DTEC and AE. For DTEC and Dst pair, the null hypothesis is not rejected for the storm on March 19 at the Bangalore location. For most of the storm use cases, the test statistic value is higher as compared to the critical value for DTEC and Dst pair for Bangalore. Hence, it can be concluded that for most of the cases the null hypothesis can be rejected. This is also in line with the fact the geomagnetic storms can be well explained by the Dst index in equatorial and low-latitude regions. Both the tests (eigen and trace) confirmed that most of the storm days have cointegrating vectors indicating that the geomagnetic indices Dst and deviation in TEC have a long-run linkage at Bangalore station.

Table 4 shows the cointegration test results for DTEC and AE pair. For most of the storm cases listed, the null hypothesis is rejected, and test statistics is higher than the critical value except for storm that occurred on March 19, 2015, April 16, 2015, and Jun 22, 2015. The storm on June 22 has its main phase around 20 UTC, and the AE index shows enhancement only after 15 UT. Hence, for most of the day, the AE is low. Similarly, the storm on April 16 is a moderate storm and the AE is almost constant at $800 \mathrm{nT}$ for the entire day. The AE index is a suitable measure of substorms. It is seen 
Table 3 Johansen cointegration rank test results for DTEC and Dst for the Bangalore location

\begin{tabular}{|c|c|c|c|c|c|c|c|c|c|}
\hline \multirow[t]{2}{*}{ S.No } & \multirow[t]{2}{*}{$\begin{array}{l}\text { Storm } \\
\text { date }\end{array}$} & \multicolumn{4}{|c|}{$\begin{array}{l}\text { Test using trace test statistic with } 5 \% \\
\text { significance level for DTEC and Dst pair }\end{array}$} & \multicolumn{4}{|c|}{$\begin{array}{l}\text { Test using maximum eigenvalue test } \\
\text { statistic with } 5 \% \text { significance level for } \\
\text { DTEC and Dst pair }\end{array}$} \\
\hline & & $\begin{array}{l}\text { Rank } r_{-} \\
0\end{array}$ & $\begin{array}{l}\text { Rank } r_{-} \\
1\end{array}$ & $\begin{array}{l}\text { Test } \\
\text { statistic }\end{array}$ & $\begin{array}{l}\text { Critical } \\
\text { value }\end{array}$ & $\begin{array}{l}\text { Rank } r_{-} \\
0\end{array}$ & $\begin{array}{l}\text { Rank } r_{-} \\
1\end{array}$ & $\begin{array}{l}\text { Test } \\
\text { statistic } \\
\end{array}$ & $\begin{array}{l}\text { Critical } \\
\text { value }\end{array}$ \\
\hline \multirow[t]{2}{*}{1} & \multirow{2}{*}{$\begin{array}{l}01-03- \\
2015\end{array}$} & 0 & 2 & 26.43 & 18.40 & 0 & 1 & 20.52 & 17.15 \\
\hline & & 1 & 2 & 5.908 & 3.841 & 1 & 2 & 5.908 & 3.841 \\
\hline \multirow[t]{2}{*}{2.} & \multirow{2}{*}{$\begin{array}{l}02-3- \\
2015\end{array}$} & 0 & 2 & 26.43 & 18.40 & 0 & 1 & 20.52 & 17.15 \\
\hline & & 1 & 2 & 5.908 & 3.841 & 1 & 2 & 5.908 & 3.841 \\
\hline \multirow[t]{2}{*}{3} & \multirow{2}{*}{$\begin{array}{l}17-03- \\
2015\end{array}$} & 0 & 2 & 28.31 & 18.40 & 0 & 1 & 21.09 & 17.15 \\
\hline & & 1 & 2 & 7.216 & 3.841 & 1 & 2 & 7.216 & 3.841 \\
\hline \multirow[t]{2}{*}{4} & \multirow{2}{*}{$\begin{array}{l}19-03- \\
2015\end{array}$} & 0 & 2 & 26.84 & 18.40 & 0 & 1 & 23.38 & 17.15 \\
\hline & & 1 & 2 & $3.464^{*}$ & 3.841 & 1 & 2 & $3.464^{*}$ & 3.841 \\
\hline \multirow[t]{2}{*}{5} & \multirow{2}{*}{$\begin{array}{l}21-03- \\
2015\end{array}$} & 0 & 2 & 35.20 & 18.40 & 0 & 1 & 31.71 & 17.15 \\
\hline & & 1 & 2 & 3.487 & 3.841 & 1 & 2 & 3.487 & 3.841 \\
\hline \multirow[t]{2}{*}{6} & \multirow{2}{*}{$\begin{array}{l}22-03- \\
2015\end{array}$} & 0 & 2 & 34.93 & 18.40 & 0 & 1 & 28.16 & 17.15 \\
\hline & & 1 & 2 & 6.774 & 3.841 & 1 & 2 & 6.774 & 3.841 \\
\hline 7 & $\begin{array}{l}16-04- \\
2015\end{array}$ & 0 & 2 & 17.88 & 18.40 & 0 & 1 & 13.50 & 17.15 \\
\hline \multirow[t]{2}{*}{8} & \multirow{2}{*}{$\begin{array}{l}22-06- \\
2015\end{array}$} & 0 & 2 & 33.02 & 18.40 & 0 & 1 & 28.51 & 17.15 \\
\hline & & 1 & 2 & 4.510 & 3.841 & 1 & 2 & 4.510 & 3.841 \\
\hline \multirow[t]{2}{*}{9} & \multirow{2}{*}{$\begin{array}{l}23-06- \\
2015\end{array}$} & 0 & 2 & 29.29 & 18.40 & 0 & 1 & 18.78 & 17.15 \\
\hline & & 1 & 2 & 10.51 & 3.841 & 1 & 2 & 10.51 & 3.841 \\
\hline \multirow[t]{2}{*}{10} & \multirow{2}{*}{$\begin{array}{l}20-12- \\
2015\end{array}$} & 0 & 2 & 35.58 & 18.40 & 0 & 1 & 23.93 & 17.15 \\
\hline & & 1 & 2 & 11.65 & 3.841 & 1 & 2 & 11.65 & 3.841 \\
\hline \multirow[t]{2}{*}{11} & \multirow{2}{*}{$\begin{array}{l}21-12- \\
2015\end{array}$} & 0 & 2 & 50.48 & 18.40 & 0 & 2 & 50.48 & 18.40 \\
\hline & & 1 & 2 & 11.69 & 3.841 & 1 & 2 & 11.69 & 3.841 \\
\hline \multirow[t]{2}{*}{12} & \multirow{2}{*}{$\begin{array}{l}31-12- \\
2015\end{array}$} & 0 & 2 & 27.83 & 18.40 & 0 & 1 & 21.34 & 17.15 \\
\hline & & 1 & 2 & 6.491 & 3.841 & 1 & 2 & 6.491 & 3.841 \\
\hline
\end{tabular}

*Rejection of the null hypothesis at $5 \%$ level of significance

that for all cases of substorm on 21-3-2015 and 22-3-2015, the DTEC and AE reject the null hypothesis.

\section{Results of the cointegration test for Hyderabad}

The results of Johansen's maximum eigenvalue and trace tests for Hyderabad are given in Tables 5 and 6 . All tests are conducted with $5 \%$ critical value, since the maximum eigenvalue and trace test statistics values are higher than $5 \%$ critical values and the alternative of one or more cointegrating vectors is accepted. Table 5 shows the results for twelve geomagnetic storm days for the year 2015. The test is done pairwise between DTEC and Dst and DTEC and AE. Both the tests confirm that most of the storm days under consideration have cointegrating vectors indicating that the geomagnetic indices and deviation in TEC have a long-run linkage. Most of the storm use cases have a higher test statistic value as compared to the critical value for DTEC and Dst pair for Hyderabad. Hence, it can be concluded that for most of the cases the null hypothesis can be rejected and there exists long-run cointegration. 
Table 4 Johansen cointegration rank test results for DTEC and AE pair for the Bangalore location

\begin{tabular}{|c|c|c|c|c|c|c|c|c|c|}
\hline \multirow[t]{2}{*}{ S.No } & \multirow[t]{2}{*}{$\begin{array}{l}\text { Storm } \\
\text { date }\end{array}$} & \multicolumn{4}{|c|}{$\begin{array}{l}\text { Test using trace test statistic with } 5 \% \\
\text { significance level for DTEC and AE pair }\end{array}$} & \multicolumn{4}{|c|}{$\begin{array}{l}\text { Test using maximum eigenvalue test } \\
\text { statistic with } 5 \% \text { significance level for } \\
\text { DTEC and AE pair }\end{array}$} \\
\hline & & $\begin{array}{l}\text { Rank } r_{-} \\
0\end{array}$ & $\begin{array}{l}\text { Rank } r_{-} \\
1\end{array}$ & $\begin{array}{l}\text { Test } \\
\text { statistic }\end{array}$ & $\begin{array}{l}\text { Critical } \\
\text { value }\end{array}$ & $\begin{array}{l}\text { Rank } r_{-} \\
0\end{array}$ & $\begin{array}{l}\text { Rank } r_{-} \\
1\end{array}$ & $\begin{array}{l}\text { Test } \\
\text { statistic } \\
\end{array}$ & $\begin{array}{l}\text { Critical } \\
\text { value }\end{array}$ \\
\hline \multirow[t]{2}{*}{1} & \multirow{2}{*}{$\begin{array}{l}01-03- \\
2015\end{array}$} & 0 & 2 & 39.07 & 18.40 & 0 & 1 & 34.22 & 17.15 \\
\hline & & 1 & 2 & 4.858 & 3.841 & 1 & 2 & 4.858 & 3.841 \\
\hline \multirow[t]{2}{*}{2.} & \multirow{2}{*}{$\begin{array}{l}02-3- \\
2015\end{array}$} & 0 & 2 & 39.07 & 18.40 & 0 & 1 & 34.22 & 17.15 \\
\hline & & 1 & 2 & 4.858 & 3.841 & 1 & 2 & 4.858 & 3.841 \\
\hline \multirow[t]{2}{*}{3} & \multirow{2}{*}{$\begin{array}{l}17-03- \\
2015\end{array}$} & 0 & 2 & 34.69 & 18.40 & 0 & 1 & 34.22 & 17.15 \\
\hline & & 1 & 2 & 6.621 & 3.841 & 1 & 2 & 4.858 & 3.841 \\
\hline 4 & $\begin{array}{l}19-03- \\
2015\end{array}$ & 0 & 2 & $12.78^{*}$ & 18.40 & 0 & 1 & $9.302^{*}$ & 17.15 \\
\hline \multirow[t]{2}{*}{5} & \multirow{2}{*}{$\begin{array}{l}21-03- \\
2015\end{array}$} & 0 & 2 & 31.42 & 18.40 & 0 & 1 & 26.67 & 17.15 \\
\hline & & 1 & 2 & 4.748 & 3.841 & 1 & 2 & 4.748 & 3.841 \\
\hline \multirow[t]{2}{*}{6} & \multirow{2}{*}{$\begin{array}{l}22-03- \\
2015\end{array}$} & 0 & 2 & 30.17 & 18.40 & 0 & 1 & 19.20 & 17.15 \\
\hline & & 1 & 2 & 10.97 & 3.841 & 1 & 2 & 10.97 & 3.841 \\
\hline 7 & $\begin{array}{l}16-04- \\
2015\end{array}$ & 0 & 2 & $6.939^{*}$ & 18.40 & 0 & 1 & $6.160^{*}$ & 17.15 \\
\hline 8 & $\begin{array}{l}22-06- \\
2015\end{array}$ & 0 & 2 & $6.939^{*}$ & 18.40 & 0 & 2 & $6.939^{*}$ & 17.15 \\
\hline \multirow[t]{2}{*}{9} & \multirow{2}{*}{$\begin{array}{l}23-06- \\
2015\end{array}$} & 0 & 2 & 46.34 & 18.40 & 0 & 1 & 37.29 & 17.15 \\
\hline & & 1 & 2 & 9.050 & 3.841 & 1 & 2 & 9.050 & 3.841 \\
\hline \multirow[t]{2}{*}{10} & \multirow{2}{*}{$\begin{array}{l}20-12- \\
2015\end{array}$} & 0 & 2 & 36.56 & 18.40 & 0 & 1 & 27.67 & 17.15 \\
\hline & & 1 & 2 & 8.888 & 3.841 & 1 & 2 & 8.888 & 3.841 \\
\hline \multirow[t]{2}{*}{11} & \multirow{2}{*}{$\begin{array}{l}21-12- \\
2015\end{array}$} & 0 & 2 & 41.27 & 18.40 & 0 & 1 & 28.24 & 18.40 \\
\hline & & 1 & 2 & 13.03 & 3.841 & 1 & 2 & 13.03 & 3.841 \\
\hline \multirow[t]{2}{*}{12} & \multirow{2}{*}{$\begin{array}{l}31-12- \\
2015\end{array}$} & 0 & 2 & 32.77 & 18.40 & 0 & 1 & 20.14 & 17.15 \\
\hline & & 1 & 2 & 12.63 & 3.841 & 1 & 2 & 12.63 & 3.841 \\
\hline
\end{tabular}

*Rejection of the null hypothesis at $5 \%$ level of significance

Table 6 shows the cointegration test results for DTEC and AE pair. For most of the storm cases, the null hypothesis is rejected. The test statistics for eigenvalue is lower than the critical value for the storm on March 22, 2015, April 16, 2015, and Jun 22, 2015. The null hypothesis cannot be rejected for these days.

\section{Granger causality test}

The causality tests are based on the null hypothesis as follows: "Coefficients of past values in the regression equation is zero." Furthermore, the significance value is set ( $p$ $=0.05)$ and if the $p$ value obtained from the test is less than the significance level of 0.05 , then the null hypothesis is rejected. This means that the past values of time series $(X)$ do not cause the series $(Y)$ to be rejected. The hypothesis is tested using the $F$ test. The causality is tested pairwise. For causality to exist between the time series, the null hypothesis must be rejected. For testing causality between DTEC and Dst and AE, the null hypothesis is stated as "Past value of the Dst index $\left(\mathrm{X}_{1}\right)$ and $\mathrm{AE}$ index $\left(\mathrm{X}_{2}\right)$ do not cause a deviation in VTEC (DTEC)." 
Table 5 Johansen cointegration rank test results for DTEC and Dst for the Hyderabad location

\begin{tabular}{|c|c|c|c|c|c|c|c|c|c|}
\hline \multirow[t]{2}{*}{ S.No } & \multirow[t]{2}{*}{$\begin{array}{l}\text { Storm } \\
\text { date }\end{array}$} & \multicolumn{4}{|c|}{$\begin{array}{l}\text { Trace test statistic with } 5 \% \text { significance } \\
\text { level for DTEC and Dst pair }\end{array}$} & \multicolumn{4}{|c|}{$\begin{array}{l}\text { Maximum eigenvalue test statistic with } \\
5 \% \text { significance level for DTEC and Dst } \\
\text { pair }\end{array}$} \\
\hline & & $\begin{array}{l}\text { Rank } r_{-} \\
0\end{array}$ & $\begin{array}{l}\text { Rank } r_{-} \\
1\end{array}$ & $\begin{array}{l}\text { Test } \\
\text { statistic }\end{array}$ & $\begin{array}{l}\text { Critical } \\
\text { value }\end{array}$ & $\begin{array}{l}\text { Rank } r_{-} \\
0\end{array}$ & $\begin{array}{l}\text { Rank } r_{-} \\
1\end{array}$ & $\begin{array}{l}\text { Test } \\
\text { statistic }\end{array}$ & $\begin{array}{l}\text { Critical } \\
\text { value }\end{array}$ \\
\hline \multirow[t]{2}{*}{1} & \multirow{2}{*}{$\begin{array}{l}01-03- \\
2015\end{array}$} & 0 & 2 & 29.21 & 18.40 & 0 & 1 & 22.41 & 17.15 \\
\hline & & 1 & 2 & 6.798 & 3.841 & 1 & 2 & 6.798 & 3.841 \\
\hline \multirow[t]{2}{*}{2.} & \multirow{2}{*}{$\begin{array}{l}02-3- \\
2015\end{array}$} & 0 & 2 & 29.21 & 18.40 & 0 & 1 & 22.41 & 17.15 \\
\hline & & 1 & 2 & 6.798 & 3.841 & 1 & 2 & 6.798 & 3.841 \\
\hline \multirow[t]{2}{*}{3} & \multirow{2}{*}{$\begin{array}{l}17-03- \\
2015\end{array}$} & 0 & 2 & 25.73 & 18.41 & 0 & 1 & 21.99 & 17.15 \\
\hline & & 1 & 2 & $3.736^{*}$ & 3.841 & 1 & 2 & $3.736^{*}$ & 3.841 \\
\hline \multirow[t]{2}{*}{4} & \multirow{2}{*}{$\begin{array}{l}19-03- \\
2015\end{array}$} & 0 & 2 & 23.72 & 18.40 & 0 & 1 & 19.33 & 17.15 \\
\hline & & 1 & 2 & 4.385 & 3.841 & 1 & 2 & 4.385 & 3.841 \\
\hline \multirow[t]{2}{*}{5} & \multirow{2}{*}{$\begin{array}{l}21-03- \\
2015\end{array}$} & 0 & 2 & 30.29 & 18.40 & 0 & 1 & 22.60 & 17.15 \\
\hline & & 1 & 2 & 7.693 & 3.841 & 1 & 2 & 7.693 & 3.841 \\
\hline \multirow[t]{2}{*}{6} & \multirow{2}{*}{$\begin{array}{l}22-03- \\
2015\end{array}$} & 0 & 2 & 22.22 & 18.40 & 0 & 1 & 17.22 & 17.15 \\
\hline & & 1 & 2 & 4.993 & 3.841 & 1 & 2 & 4.993 & 3.841 \\
\hline \multirow[t]{2}{*}{7} & \multirow{2}{*}{$\begin{array}{l}16-04- \\
2015\end{array}$} & 0 & 2 & 18.44 & 18.40 & 0 & 1 & 13.41 & 17.15 \\
\hline & & 1 & 2 & 5.032 & 3.841 & & & & \\
\hline \multirow[t]{2}{*}{8} & \multirow{2}{*}{$\begin{array}{l}22-06- \\
2015\end{array}$} & 0 & 2 & 38.15 & 18.40 & 0 & 1 & 34.55 & 17.15 \\
\hline & & 1 & 2 & $3.610^{*}$ & 3.841 & 1 & 2 & $3.610^{*}$ & 3.841 \\
\hline 9 & $\begin{array}{l}23-06- \\
2015\end{array}$ & 0 & 2 & 16.84 & 18.40 & 0 & 1 & 10.35 & 17.15 \\
\hline \multirow[t]{2}{*}{10} & \multirow{2}{*}{$\begin{array}{l}20-12- \\
2015\end{array}$} & 0 & 2 & 33.79 & 18.40 & 0 & 1 & 22.92 & 17.15 \\
\hline & & 1 & 2 & 10.87 & 3.841 & 1 & 2 & 10.87 & 3.841 \\
\hline \multirow[t]{2}{*}{11} & \multirow{2}{*}{$\begin{array}{l}21-12- \\
2015\end{array}$} & 0 & 2 & 49.49 & 18.40 & 0 & 1 & 37.95 & 18.40 \\
\hline & & 1 & 2 & 11.54 & 3.841 & 1 & 2 & 11.54 & 3.841 \\
\hline \multirow[t]{2}{*}{12} & \multirow{2}{*}{$\begin{array}{l}31-12- \\
2015\end{array}$} & 0 & 2 & 26.34 & 18.40 & 0 & 1 & 21.27 & 17.15 \\
\hline & & 1 & 2 & 5.066 & 3.841 & 1 & 2 & 5.066 & 3.841 \\
\hline
\end{tabular}

*Rejection of the null hypothesis at $5 \%$ level of significance

Furthermore, as all the time series under consideration are non-stationary, hence the cointegration test results are considered before performing the Granger causality test. Hence, whenever the series are cointegrated, the causality test based on VECM is carried out or else they are fitted with VAR as mentioned in the "Granger causality test" section. The vector error correction model (VECM) expresses the long-run dynamics of the process including error correction terms $\left(\alpha \beta^{\prime} Y_{t-1}\right)$ which is the measure of the deviation from the stationary mean at time $t-1$ and is given as:

$$
\Delta Y_{t}=c+\prod Y_{t-1}+\sum_{i=1}^{p-1} \Gamma_{i} \Delta Y_{t-i}+\epsilon_{t}
$$

where $\Pi=\alpha \beta^{\prime}$ and $c$ are the drift coefficient and $\Pi=\sum_{i=1}^{p} A i-I$ and $\Gamma \mathrm{i}=-\sum_{j=i+1}^{p} \mathrm{Aj}$. 
Table 6 Johansen cointegration rank test results for DTEC and AE pair for the Hyderabad location

\begin{tabular}{|c|c|c|c|c|c|c|c|c|c|}
\hline \multirow[t]{2}{*}{ S.No } & \multirow[t]{2}{*}{$\begin{array}{l}\text { Storm } \\
\text { date }\end{array}$} & \multicolumn{4}{|c|}{$\begin{array}{l}\text { Test using trace test statistic with } 5 \% \\
\text { significance level for DTEC and AE pair }\end{array}$} & \multicolumn{4}{|c|}{$\begin{array}{l}\text { Test using maximum eigenvalue test } \\
\text { statistic with } 5 \% \text { significance level for } \\
\text { DTEC and AE pair }\end{array}$} \\
\hline & & $\begin{array}{l}\text { Rank } r_{-} \\
0\end{array}$ & $\begin{array}{l}\text { Rank } r_{-} \\
1\end{array}$ & $\begin{array}{l}\text { Test } \\
\text { statistic }\end{array}$ & $\begin{array}{l}\text { Critical } \\
\text { value }\end{array}$ & $\begin{array}{l}\text { Rank } r_{-} \\
0\end{array}$ & $\begin{array}{l}\text { Rank } r_{-} \\
1\end{array}$ & $\begin{array}{l}\text { Test } \\
\text { statistic }\end{array}$ & $\begin{array}{l}\text { Critical } \\
\text { value }\end{array}$ \\
\hline \multirow[t]{2}{*}{1} & \multirow{2}{*}{$\begin{array}{l}01-03- \\
2015\end{array}$} & 0 & 2 & 35.75 & 18.40 & 0 & 1 & 30.45 & 17.15 \\
\hline & & 1 & 2 & 5.301 & 3.841 & 1 & 2 & 5.301 & 3.841 \\
\hline \multirow[t]{2}{*}{2.} & \multirow{2}{*}{$\begin{array}{l}02-3- \\
2015\end{array}$} & 0 & 2 & 35.75 & 18.40 & 0 & 1 & 30.45 & 17.15 \\
\hline & & 1 & 2 & 5.301 & 3.841 & 1 & 2 & 5.301 & 3.841 \\
\hline \multirow[t]{2}{*}{3} & \multirow{2}{*}{$\begin{array}{l}17-03- \\
2015\end{array}$} & 0 & 2 & 30.01 & 18.41 & 0 & 1 & 26.65 & 17.15 \\
\hline & & 1 & 2 & 3.362 & 3.841 & 1 & 2 & 3.362 & 3.841 \\
\hline \multirow[t]{2}{*}{4} & \multirow{2}{*}{$\begin{array}{l}19-03- \\
2015\end{array}$} & 0 & 2 & 29.55 & 18.40 & 0 & 2 & 21.99 & 17.15 \\
\hline & & 1 & 2 & 7.557 & 3.841 & 1 & 2 & 7.557 & 3.841 \\
\hline \multirow[t]{2}{*}{5} & \multirow{2}{*}{$\begin{array}{l}21-03- \\
2015\end{array}$} & 0 & 2 & 35.16 & 18.40 & 0 & 1 & 30.65 & 17.15 \\
\hline & & 1 & 2 & 4.515 & 3.841 & 1 & 2 & 4.515 & 3.841 \\
\hline \multirow[t]{2}{*}{6} & \multirow{2}{*}{$\begin{array}{l}22-03- \\
2015\end{array}$} & 0 & 2 & 21.55 & 18.40 & 0 & 1 & $15.34^{*}$ & 17.15 \\
\hline & & 1 & 2 & 6.213 & 3.841 & & & & \\
\hline \multirow[t]{2}{*}{7} & \multirow{2}{*}{$\begin{array}{l}16-04- \\
2015\end{array}$} & 0 & 2 & 26.35 & 18.40 & 0 & 1 & $13.80^{*}$ & 17.15 \\
\hline & & 1 & 2 & 12.56 & 3.841 & & & & 3.841 \\
\hline 8 & $\begin{array}{l}22-06- \\
2015\end{array}$ & 0 & 2 & $12.45^{*}$ & 18.40 & 0 & 1 & $12.38^{*}$ & 17.15 \\
\hline \multirow[t]{2}{*}{9} & \multirow{2}{*}{$\begin{array}{l}23-06- \\
2015\end{array}$} & 0 & 2 & 42.24 & 18.40 & 0 & 1 & 37.78 & 17.15 \\
\hline & & 1 & 2 & 4.460 & 3.841 & 1 & 2 & 4.460 & 3.841 \\
\hline \multirow[t]{2}{*}{10} & \multirow{2}{*}{$\begin{array}{l}20-12- \\
2015\end{array}$} & 0 & 2 & 37.79 & 18.40 & 0 & 2 & 28.62 & 17.15 \\
\hline & & 1 & 2 & 9.172 & 3.841 & 1 & 2 & 9.172 & 3.841 \\
\hline \multirow[t]{2}{*}{11} & \multirow{2}{*}{$\begin{array}{l}21-12- \\
2015\end{array}$} & 0 & 2 & 40.89 & 18.40 & 0 & 1 & 32.40 & 18.40 \\
\hline & & 1 & 2 & 8.488 & 3.841 & 1 & 2 & 8.488 & 3.841 \\
\hline \multirow[t]{2}{*}{12} & \multirow{2}{*}{$\begin{array}{l}31-12- \\
2015\end{array}$} & 0 & 2 & 23.15 & 18.40 & 0 & 2 & 13.67 & 17.15 \\
\hline & & 1 & 2 & 9.476 & 3.841 & & & & \\
\hline
\end{tabular}

*Rejection of the null hypothesis at $5 \%$ level of significance

If the variables in $Y t$ have differencing order of one $(I(1))$, then the terms involving differences are stationary, and the error correction term in the VEC model introduces long-term stochastic trends between the variables.

The appropriate value of lag value $p$ is made using the Akaike Information Criterion (AIC). The causality result is represented as a matrix based on the $p$ value. The Granger causality test results on different storm days are discussed in the next section.

\section{Results of the Granger causality test}

After finding cointegration among the data series, the Granger causality is estimated between the selected pairs DTEC and Dst and DTEC and AE. The results of the Granger causality tests are presented in Table 7 which shows $F$ statistics for the causality tests between variables DTEC and Dst and DTEC and AE for Bangalore. The null hypothesis of Granger causality is rejected for most of the cases of storms and substorms. This indicates that most of the geomagnetic storms can be explained by either Dst or AE. The same procedure is repeated for Hyderabad. Table 8 summarizes the 
results of the $F$ test done for Granger causality at Hyderabad between pairs DTEC-Dst and DTEC-AE, respectively.

For both the locations, deviation in TEC could be explained by either Dst or AE depending on the nature of the storm or substorm. The difference in significance $p$ value between latitudes also clearly indicates that the impact of the storm is different at both the location, and hence, this test can help in providing results at the regional level.

\section{Conclusion}

This work probes the relationship between the GPS-derived VTEC at the location and the geomagnetic indices, Dst and $\mathrm{AE}$, through causality analysis. The geomagnetic storms can bring about a lot of irregularities in the TEC in the ionosphere causing positional errors. Hence, estimating the amount of deviation in TEC during the geomagnetic storm can improve positional accuracy. The causal inference provides intuitive ways for detecting an anomaly in the TEC variation during disturbed ionospheric conditions. It is well known that most of the geomagnetic storms can be well explained with Dst or AE index, and in this study, Granger causality between geomagnetic indices and TEC could be established for most cases. As per the causality test results, causality between deviation in TEC and both geomagnetic indices Dst and AE could not be established simultaneously for some storms. This is primarily due to the difference in their origin and type. However, causality could be established with either Dst or AE for most of the storm cases tested for the year 2015. In this paper, storms of different intensities, types, and different origins are presented. Some storms were in the main phase while some of them were storms during the recovery phase. Furthermore, the causality is tested for both recurrent and sudden commencement storms. For most of the cases, the causality could be established with suitable lag values. The storms on March 1 and 2 have a similar origin, and causality results are well aligned with Dst. For most of the storm days, all three variables DTEC, AE, and Dst are found to be

Table $7 \mathrm{~F}$ statistics results of the Granger causality test at location Bangalore with variables DTEC and Dst pair and DTEC and AE pair at 5\% significance level

\begin{tabular}{|c|c|c|c|c|c|}
\hline \multirow[t]{3}{*}{ S.No } & \multirow[t]{3}{*}{$\begin{array}{l}\text { Date of } \\
\text { the storm }\end{array}$} & \multirow{2}{*}{\multicolumn{2}{|c|}{$\begin{array}{l}\text { Null hypothesis: Dst does not Granger } \\
\text { cause deviation in TEC } \\
\text { DTEC as } Y \text { and Dst as } X\end{array}$}} & \multirow{2}{*}{\multicolumn{2}{|c|}{$\begin{array}{l}\text { Null Hypothesis: AE does not Granger } \\
\text { cause deviation in TEC } \\
\text { DTEC as } Y \text { and AE as } X\end{array}$}} \\
\hline & & & & & \\
\hline & & $p$ value & Null hypothesis & $p$ value & Null hypothesis \\
\hline 1 & 01-03-2015 & 0.00 & Rejected & 0.00 & Rejected \\
\hline 2 & 02-03-2015 & 0.003 & Rejected & 0.012 & Rejected \\
\hline 3 & $17-3-2015$ & 0.019 & Rejected & 0.00 & Rejected \\
\hline 4 & $19-3-2015$ & $0.163^{*}$ & Fails to reject & 0.00 & Rejected \\
\hline 5 & $21-3-2015$ & 0.049 & Rejected & 0.00 & Rejected \\
\hline 6 & $22-3-2015$ & 0.00 & Rejected & 0.00 & Rejected \\
\hline 7 & $16-4-2015$ & $0.311^{*}$ & Fails to reject & 0.00 & Rejected \\
\hline 8 & $22-6-2015$ & 0.019 & Rejected & $0.129^{*}$ & Fails to reject \\
\hline 9 & $23-6-2015$ & $0.816^{*}$ & Fails to reject & 0.016 & Rejected \\
\hline 10 & $20-12-2015$ & 0.00 & Rejected & 0.05 & Rejected \\
\hline 11 & $21-12-2015$ & 0.00 & Rejected & 0.00 & Rejected \\
\hline 12 & $31-12-2015$ & 0.032 & Rejected & $0.548^{*}$ & Fails to reject \\
\hline
\end{tabular}

*Rejection of the null hypothesis at $5 \%$ level of significance 
Table 8 F statistics results of the Granger causality test at location Hyderabad with variables DTEC and Dst pair and DTEC and AE pair at 5\% significance level

\begin{tabular}{|c|c|c|c|c|c|}
\hline \multirow[t]{3}{*}{ S.No } & \multirow[t]{3}{*}{$\begin{array}{l}\text { Date of } \\
\text { the storm }\end{array}$} & \multirow{2}{*}{\multicolumn{2}{|c|}{$\begin{array}{l}\text { Null hypothesis: Dst does not Granger } \\
\text { cause deviation in TEC } \\
\text { DTEC as } Y \text { and Dst as } X\end{array}$}} & \multirow{2}{*}{\multicolumn{2}{|c|}{$\begin{array}{l}\text { Null hypothesis: AE does not Granger } \\
\text { cause deviation in TEC } \\
\text { DTEC as } Y \text { and AE as } X\end{array}$}} \\
\hline & & & & & \\
\hline & & $p$ value & Null hypothesis & $p$ value & Null hypothesis \\
\hline 1 & 01-03-2015 & 0.00 & Rejected & 0 & Rejected \\
\hline 2 & 02-03-2015 & 0.019 & Rejected & 0 & Rejected \\
\hline 3 & $17-3-2015$ & $0.085^{*}$ & Rejected & 0.007 & Rejected \\
\hline 4 & 19-3-2015 & $0.162^{*}$ & Fails to reject & 0 & Rejected \\
\hline 5 & $21-3-2015$ & $0.063^{*}$ & Rejected & 0.037 & Rejected \\
\hline 6 & $22-3-2015$ & 0.06 & Rejected & $0.247^{*}$ & Fails to reject \\
\hline 7 & $16-4-2015$ & 0 & Fails to reject & 0.021 & Rejected \\
\hline 8 & $22-6-2015$ & $0.595^{*}$ & Rejected & 0.001 & Rejected \\
\hline 9 & 23-6-2015 & 0.002 & Fails to reject & 0.003 & Rejected \\
\hline 10 & $20-12-2015$ & 0.032 & Rejected & 0.003 & Rejected \\
\hline 11 & $21-12-2015$ & 0 & Rejected & 0.007 & Rejected \\
\hline 12 & $31-12-2015$ & 0.003 & Rejected & 0 & Rejected \\
\hline
\end{tabular}

*Rejection of the null hypothesis at $5 \%$ level of significance

cointegrated at both the latitudes. Thus, this indicates long-run dependence in at least one direction. The causality method can be further used for predicting the short-term TEC irregularities by using VAR or VECM models. However, further investigation with more variables and different lag values is required. The advance prediction of TEC can be helpful in mitigating ionospheric effects on trans-ionospheric communication and improve the navigation system used for critical applications especially in equatorial regions.

\section{Abbreviations}

TEC: Total Electron Content; GNSS: Global Navigation Satellite System; AE: Auroral Electrojet; Dst: Disturbance Storm Time; GPS: Global Positioning System; CMEs: Coronal Mass Ejection; CIRs: Corotating Interaction Region;

IMF: Interplanetary Magnetic Field; EEJ: Equatorial Electrojet; ADF: Augmented Dickey Fuller

Acknowledgements

Not applicable.

Authors' contributions

The idea of causality is suggested by AM, and SI has implemented the idea and verified the results. All authors have read and approved the final manuscript.

Funding

This study had no funding from any resource.

Availability of data and materials

Not applicable.

\section{Declaration}

Competing interests

The authors declare that they have no competing interests.

\section{Author details}

${ }^{1}$ Department of Electronics and Communication, Nirma Institute of Technology, Ahmedabad, Gujarat, India. ${ }^{2}$ Mukesh

Patel School of Technology Management \& Engineering, Vile Parle (West), Mumbai, India. 
Received: 25 March 2021 Accepted: 10 June 2021

Published online: 11 August 2021

\section{References}

1. Alberti T et al (2017) Timescale separation in the solar wind-magnetosphere coupling during St. Patrick's Day storms in 2013 and 2015. J Geophys Res Space Physics 122(4):4266-4283

2. Marković M (2014) Determination of total electron content in the ionosphere using GPS technology. Geonauka 2(4):1-9

3. Panda SK, Gedam SS, Jin S (2015) Ionospheric TEC variations at low latitude Indian region. In: Satellite positioningmethods, models and applications. Tech-Publisher, Rijeka, pp 149-174

4. Chakraborty $\mathrm{M}$ et al (2015) Effects of geomagnetic storm on low latitude ionospheric total electron content: a case study from Indian sector. J Earth Syst Sci 124(5):1115-1126. https://doi.org/10.1007/s12040-015-0588-3

5. Bora S (2017) lonosphere and radio communication. Resonance 22(2):123-133. https:/doi.org/10.1007/s12045-017-0443-8

6. Ya'acob N, Abdullah M, Ismail M (2010) GPS total electron content (TEC) prediction at ionosphere layer over the equatorial region. In: Trends in Telecommunications Technologies

7. Nayir H et al (2007) GPS/TEC estimation with IONOLAB method. 2007 3rd International Conference on Recent Advances in Space Technologies. IEEE, Istanbul

8. Michalek G, Gopalswamy N, Xie H (2007) Width of radio-loud and radio-quiet CMEs. Sol Phys 246(2):409-414. https://doi. org/10.1007/s11207-007-9062-y

9. Zhang J et al (2007) Solar and interplanetary sources of major geomagnetic storms (Dst $\leq-100 \mathrm{nT}$ ) during 1996-2005. J Geophys Res Space Physics 112(A10)

10. Jin $S$, Jin R, Kutoglu H (2017) Positive and negative ionospheric responses to the March 2015 geomagnetic storm from BDS observations. J Geod 91(6):613-626. https://doi.org/10.1007/s00190-016-0988-4

11. Wang W et al (2010) lonospheric response to the initial phase of geomagnetic storms: common features. J Geophys Res Space Physics 115:A7

12. Kane RP (2009) Evolution of Dst and auroral indices during some severe geomagnetic storms. Rev Bras Geofísica 27(2): $151-163$

13. Adebesin $\mathrm{BO}$ (2016) Investigation into the linear relationship between the $\mathrm{AE}$, Dst and ap indices during different magnetic and solar activity conditions. Acta Geodaetica Geophysica 51(2):315-331. https://doi.org/10.1007/s40328-0150128-2

14. Bergin A, Chapman SC, Gjerloev JW (2020) AE, DST and their SuperMAG counterparts: The effect of improved spatial resolution in geomagnetic indices. J Geophys Res Space Phys 125:2020JA027828. https://doi.org/10.1029/2020JA027828

15. Bhattarai N, Narayan P Chap again, Adhikari B (2016) Total electron content and electron density profile observations during geomagnetic storms using COSMIC satellite data. Discovery 52(250):1979-1990

16. Pallocchia $\mathrm{G}$ et al (2008) AE index forecast at different time scales through an ANN algorithm based on L1 IMF and plasma measurements. J Atmos Sol Terr Phys 70(2-4):663-668

17. Camporeale E, Wing S, Johnson J (eds) (2018) Machine learning techniques for space weather. Elsevier

18. Immel TJ, Mannucci AJ (2013) Ionospheric redistribution during geomagnetic storms. J Geophys Res Space Physics 118(12):7928-7939. https://doi.org/10.1002/2013JA018919

19. Guo X, Wei B, Qihao F (2017) Granger causality test of the relationship between export and economic growth in Central Jiangsu region. 2017 4th International Conference on Industrial Economics System and Industrial Security Engineering (IEIS). IEEE, Kyoto

20. Seth A (2007) Granger causality. Scholarpedia 2(7):1667

21. Papana A et al (2014) Identifying causal relationships in case of non-stationary time series. Department of Economics of the University of Macedonia, Thessaloniki

22. Granger CWJ (2004) Time series analysis, cointegration, and applications. Am Econ Rev 94(3):421-425

23. Wu CC, Liou K, Lepping RP, Hutting L, Plunkett S, Howard RA, Socker D (2016) The first super geomagnetic storm of solar cycle 24:"The St. Patrick's day event (17 March 2015)". Earth Planets Space 68(1):1-12

24. Arikan FEZA et al (2008) Estimation of single station interfrequency receiver bias using GPS-TEC. Radio Sci 43(4). https:// doi.org/10.1029/2007RS003785

\section{Publisher's Note}

Springer Nature remains neutral with regard to jurisdictional claims in published maps and institutional affiliations.

\section{Submit your manuscript to a SpringerOpen ${ }^{\circ}$ journal and benefit from:}

- Convenient online submission

- Rigorous peer review

- Open access: articles freely available online

- High visibility within the field

- Retaining the copyright to your article

Submit your next manuscript at $\boldsymbol{s p r i n g e r o p e n . c o m ~}$ 